\title{
Short-term fluctuations south of Japan and their relationship with the Kuroshio path: 8- to 36-day fluctuations
}

\author{
Toru Miyama • Yasumasa Miyazawa
}

Received: 12 September 2013 / Accepted: 27 January 2014 / Published online: 26 February 2014

(C) The Author(s) 2014. This article is published with open access at Springerlink.com

\begin{abstract}
To detect short-term fluctuations south of Japan, we applied wavelet analysis to ocean reanalysis data of the Japan Coastal Ocean Predictability Experiment 2 with a horizontal resolution of $1 / 36^{\circ}$. It was found that fluctuations of the 8 - to 36-day period band appear as frontal waves in the Kuroshio Current. The amplitude of the fluctuations increases toward the downstream of Cape Shionomisaki. The fluctuations have a wavelength of about $300 \mathrm{~km}$, and the signals propagate eastward. The fluctuations of the 8- to 36-day period band are stronger during the period of the nearshore non-largemeander Kuroshio path than during the period of the offshore non-large-meander Kuroshio path. We suggest that the 8- to 36-day fluctuation is a result of the instability of the accelerated velocity of the Kuroshio Current downstream of Cape Shionomisaki.
\end{abstract}

Keywords Kuroshio path · Short-term fluctuation · Instability $\cdot$ Frontal wave $\cdot$ Wavelet $\cdot$ Ocean reanalysis

\section{Introduction}

The fluctuations of the strong Kuroshio Current, which flows near the southern coast of Japan, strongly affect the coastal environment. The region discussed in this paper (Fig. 1) is a unique location where the Kuroshio path changes with time

Responsible Editor: Leo Oey

This article is part of the Topical Collection on the 5th International Workshop on Modelling the Ocean (IWMO) in Bergen, Norway 17-20 June 2013

T. Miyama $(\bowtie) \cdot$ Y. Miyazawa

Research Institute for Global Change, Japan Agency for

Marine-Earth Science and Technology, 3173-25 Showamachi,

Kanazawa-ku, Yokohama 236-0001, Japan

e-mail: tmiyama@jamstec.go.jp dramatically (Kawabe 1985). The Kuroshio has bimodal paths: a large-meander path and a non-large-meander path. The non-large-meander path is further classified into a nearshore non-large-meander path and an offshore non-largemeander path, which are schematically shown in Fig. 1. While the Kuroshio large-meander occurs with a primary period of about 20 years and secondary period of 7 to 8.5 years, the switch between the nearshore and offshore paths happens with a primary period of 1.6-1.8 years along with 110-day, 195day, and annual periods (Kawabe 1987).

In addition to these path shifts, there are active short-term fluctuations off the southern coast of Japan. In this paper, short-term fluctuation means fluctuations of periods less than 80 days. Past studies have reported the existence of fluctuations of roughly 10- to 30-day period (Taft 1978; Taira and Teramoto 1981; Kimura and Sugimoto 1987, 1993; Kasai et al. 1993; Ramp et al. 2008). The fluctuations of this period appear as frontal waves of the Kuroshio. From hydrographic data, Taft (1978) found an eastward propagating wave having a wavelength of $330 \mathrm{~km}$ and a phase speed of $0.14 \mathrm{~m} / \mathrm{s}$. From velocity observations off Cape Shionomisaki, Kimura and Sugimoto (1993) estimated dominant periods of 5-8, 10-12, and 17-19 days with wavelengths of 100, 200, and $400 \mathrm{~km}$, respectively. The frontal waves stimulate exchange between coastal waters off the southern coast of Japan and the waters of the Kuroshio. Because of the water exchange, the short-term fluctuations affect the supply of nutrients (Kimura et al. 1997), primary production (Kimura et al. 1997; Ramp et al. 2008), and fishery conditions (Kimura and Sugimoto 1987; Kasai et al. 2002; Waseda and Mitsudera 2002; Okazaki et al. 2003). A fluctuation of a period of around 50- to 70-day, which is another fluctuation, is related to the S-shaped meandering pattern of the Kuroshio around the Izu Ridge (Kasai et al. 1993; Mitsudera et al. 2006; Takahashi et al. 2011).

Some studies have shown that the periodicities of shortterm fluctuations changed with the Kuroshio path. Takahashi 


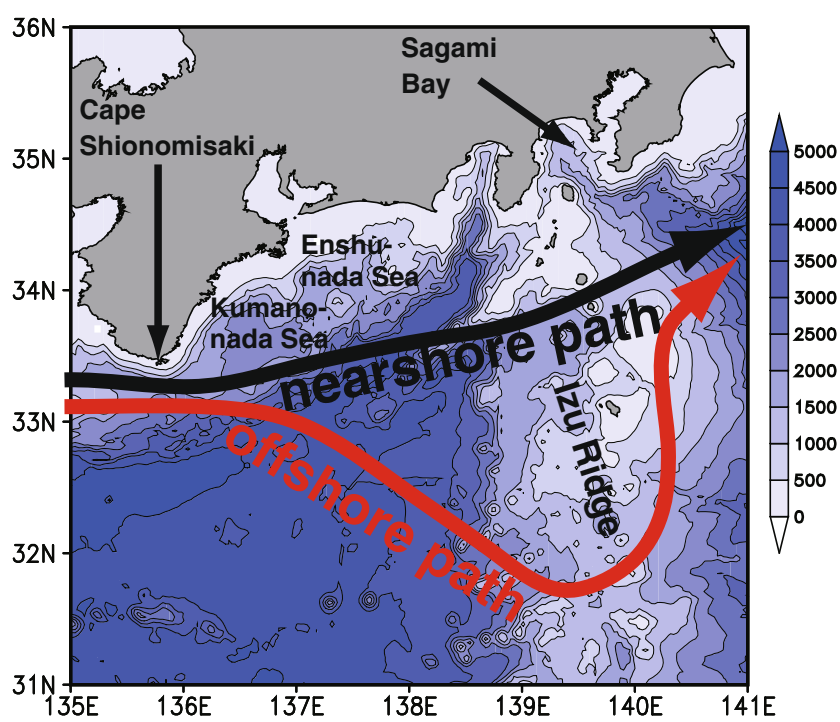

Fig. 1 Map off the southern coast of Japan. Color shading and thin contour lines show bottom topography (meter). The nearshore non-largemeander path and the offshore non-large-meander path of the Kuroshio Current are schematically illustrated

et al. (2011) found that a period of less than 40 days became weak in Sagami Bay after the transition from a nearshore nonlarge-meander path to an offshore non-large-meander path around June 3, 2008. Instead, fluctuations of 50- to 70-day periods became dominant. This is consistent with the observation by Kasai et al. (1993) in that fluctuations of a 50-day period were dominant only when the Kuroshio took an offshore non-large-meander path.

Past observations of short-term fluctuations have been conducted in limited locations and periods. Therefore, descriptions of short-term fluctuations in the Kuroshio are intermittent. Satellite data of sea surface temperature (SST) and sea surface heights (SSH), which have good spatial coverage, have been used in studies on short-term fluctuations (Kasai et al. 1993; Kimura et al. 1997; Takahashi et al. 2011, 2012). Obtaining SST images from satellites, however, is often hampered by clouds. Since SSH observations by satellite altimeters usually have a 7 - to 10-day time resolution, it is difficult to capture fluctuations of 10- to 30-day periods. On the other hand, ocean assimilation data can compensate for missing observational data in space and time with the help of a numerical model. The main objective of this study is to describe the short-term fluctuations of the Kuroshio using an ocean assimilation dataset, the Japan Coastal Ocean Predictability Experiment 2 (JCOPE2) reanalysis. We are particularly interested in how the short-term fluctuation responds to shifts in the Kuroshio path with time. Among the Kuroshio paths, we investigate the shifts between the nearshore and offshore nonlarge-meander paths.

We aim to determine not only the distribution of the fluctuations but also the time fluctuations of these distributions. Therefore, we used a wavelet analysis, which provides information regarding the amplitude of periodic signals from a time series and the fluctuation of the amplitude with time. Because past studies have identified two types of fluctuations, 10- to 30-day and 50 to 70-day fluctuations, we classified the fluctuations into bands of 8- to 36-days and 40- to 80-days. Section 2 describes how we selected these bands. In this paper, we particularly address the 8- to 36-day fluctuations.

This paper is organized as follows. In Section 2, we introduce the data used in this study, i.e., the JCOPE2 reanalysis dataset. In addition, we explain the wavelet analysis used to describe short-term fluctuations. In Section 3, we show the distribution of the fluctuations and its relationship with the Kuroshio path. In Section 4, we describe typical structures of the 8- to 36-day fluctuations. In Section 5, we show the vertical structure. In Section 6, we investigate the relationship of the fluctuations with the Kuroshio velocity. In Section 7, we summarize and discuss the results.

\section{Data and methods}

\subsection{Data}

The ocean reanalysis data used in this study is a product of the JCOPE2 (Miyazawa et al. 2009). This dataset has a horizontal resolution of $1 / 36^{\circ}, 46$ vertical levels, and covers the area $28^{\circ} \mathrm{N}-$ $36^{\circ} \mathrm{N}, 128^{\circ} \mathrm{E}-142^{\circ} \mathrm{E}$. In this paper, we particularly discuss the region from around Cape Shionomisaki to around the Izu Ridge $\left(135-140^{\circ} \mathrm{E}\right.$; Fig. 1). The lateral boundary conditions were determined from the standard JCOPE2 reanalysis (Miyazawa et al. 2009) using a one-way nesting method with a flow relaxation scheme (Oey and Chen 1992; Guo et al. 2003).

The dataset in this study is a revised version of that used in Miyama and Miyazawa (2013). While the model used in Miyama and Miyazawa (2013) was forced by the wind stress and heat flux fields of the 6-hourly National Centers for Environmental Prediction/National Center for Atmospheric Research reanalysis data $\left(2.5 \times 2.5^{\circ}\right.$ horizontal resolution; Kalnay et al. 1996), the reanalysis used in this study was forced by the 3-hourly data of the Japan Meteorological Agency Meso Scale Model analysis (MSM; $0.125 \times 0.1^{\circ}$ horizontal resolution; Saito et al. 2007). The available dataset in this study includes daily-mean data, spanning about five and a quarter years (February 23, 2006 to May 31, 2011), which is longer than the roughly four and half years (August 2003 to December 2007) of the dataset used by Miyama and Miyazawa (2013). Note that the dataset used in this study does not include the large-meander period from the second half of 2004 to the first half of 2005 (Miyazawa et al. 2008). Therefore, we discuss the short-term fluctuations during the periods of the nearshore non-large-meander and the offshore non-large-meander paths of the Kuroshio. Hereafter, we simply refer to these paths as the nearshore and the offshore paths, 
omitting the term "non-large-meander." We can better analyze the short-term fluctuations in these nearshore and offshore paths from the longer data period (more than five years) than from the period in the data used by Miyama and Miyazawa (2013). We cannot use the whole period of the data in Miyama and Miyazawa (2013) continuously because of about 1 year of the large-meander path from the second half of 2004 to the first half of 2005, which was a state dynamically different form the rest of the period. The overlapping period between data used in this study and that in Miyama and Miyazawa (2013) shows qualitatively the same results (not shown).

\subsection{Wavelet analysis}

We used the continuous wavelet analysis described in Torrence and Compo (1998). Examples of the wavelet analysis results are presented in Figs. 2, 3, and 4. Figure 2a shows the time series for $\mathrm{SSH}$ at $139^{\circ} \mathrm{E}, 33.25^{\circ} \mathrm{N}$, and Fig. $2 \mathrm{~b}$ shows the normalized wavelet power spectrum of this time series using the Morlet wavelet. There are significant short-term fluctuations in the wavelet power spectrum in periods of less than 80 days.

By averaging the wavelet spectrum over the whole time period (Section 5a of Torrence and Compo 1998), we can obtain the global wavelet power spectrum (solid line in

a) Sea Level

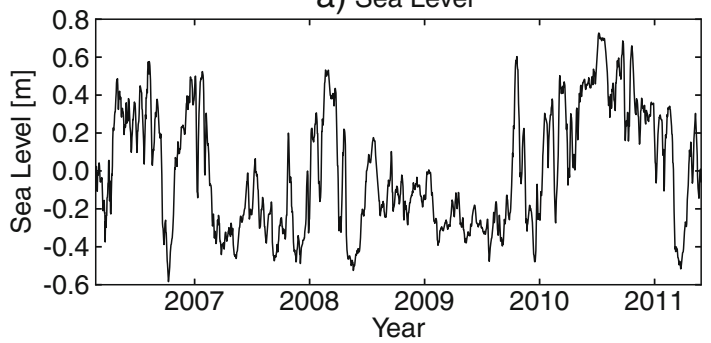

b) Sea Level Wavelet Power Spectrum (Morlet)

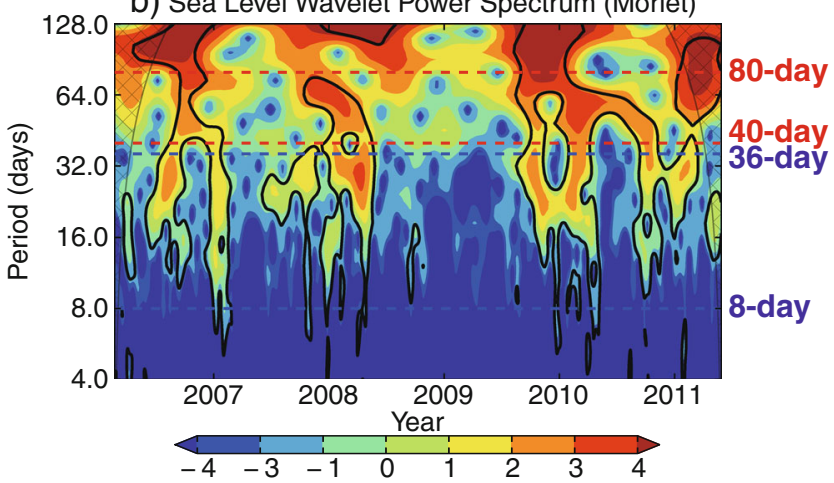

Fig. 2 a Time series of the sea level at $139^{\circ} \mathrm{E} 33.25^{\circ} \mathrm{N}$. b The local wavelet power spectrum of the time series using the Morlet wavelet, normalized by $1 / \sigma^{2}\left(\sigma^{2}=0.54 \mathrm{~m}^{2}\right)$ (color shadings). The vertical axis is the wavelet scale (periods in days). The bottom axis is time (year). Thick contours enclose regions of greater than $95 \%$ confidence for a red-noise process with a lag-1 coefficient of 0.99 . Cross-hatched regions indicate the "cone of influence," where edge effects become important

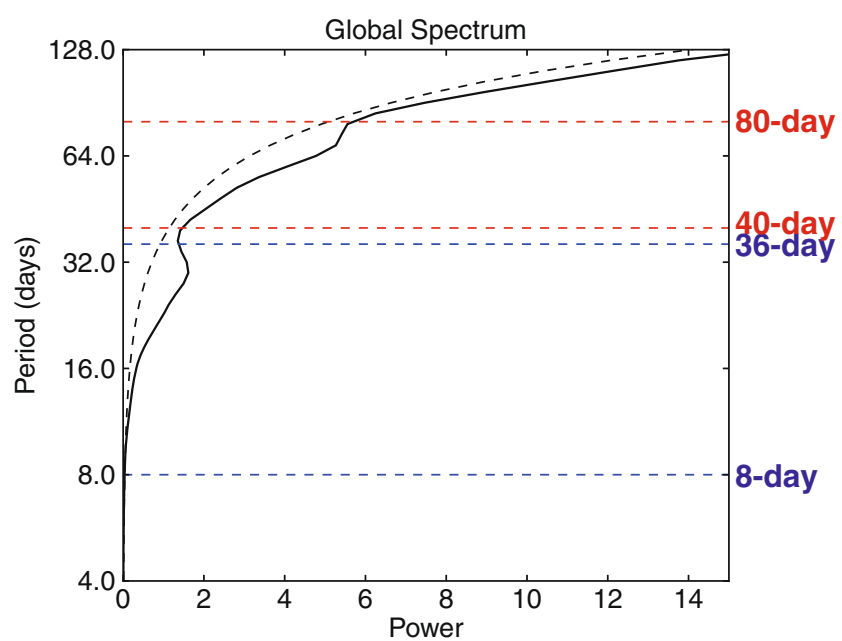

Fig. 3 Global wavelet spectrum (thick black solid line) obtained from the wavelet spectrum in Fig. 2b, and the $95 \%$ confidence level for the global wavelet spectrum (thin black dashed line), assuming a lag-1 coefficient of 0.99 . The vertical axis is the wavelet scale (periods in days). The vertical axis of the global wavelet spectrum is normalized by $1 / \sigma^{2}\left(\sigma^{2}=0.54 \mathrm{~m}^{2}\right)$

Fig. 3). Figure 3 confirms that the short-term fluctuations are significant: the global power spectrum (solid line) is above the $95 \%$ confidence level (dashed line). There are two peaks in the global spectrum: between 8 and 36 days and between 40 and 80 days. The existence of the two peaks is consistent with the past observations that there are two kinds of short-term fluctuations of periods of about 20 and 50 days (Kasai et al. 1993). From Fig. 3 and from similar results at other points (not shown), we classified the short-term fluctuations into 8- to 36-day fluctuations and 40 - to 80 -day fluctuations. However, we only discuss the 8- to 36-day fluctuations in this paper, except short descriptions on 40- to 80-day fluctuations in Appendix A.

Although some studies have detected fluctuations of around a 10-day period in addition to the fluctuations of 20to 30-day period (Kimura and Sugimoto 1993; Hinata et al. 2008; Ramp et al. 2008), we did not treat these period bands separately because we found it difficult to differentiate their peaks in this analysis. For further discussion regarding this, see Section 7. Some studies (Kimura and Sugimoto 1993; Kimura et al. 1994; Ramp et al. 2008) found fluctuations of a period of a few days. Because analyzing periods less than 8 days is difficult when using daily data, we analyzed periods more than 8 days.

By averaging the wavelet power spectrum in Fig. $2 \mathrm{~b}$ over a certain period band, we can obtain a time series of the averaged variance (square meter) (Section $5 \mathrm{~b}$ of Torrence and Compo (1998)). The solid red lines in Fig. 4 is the time series of averaged variance over 8- to 36-day. In this paper, the period-averaged power spectrum is referred to as the "variance" of the corresponding period band.

It is also possible to reconstruct the original time series inversely from the wavelet coefficients (Section $3 i$ of Torrence and Compo (1998)). By using the wavelet coefficients in a 
Fig. 4 Time series of the wavelet "variance" (red line; square meter; axis on the left) and "signal" (black line; meter; axis on the right) calculated from the time series in Fig. 2a for the 8- to 36-day period band

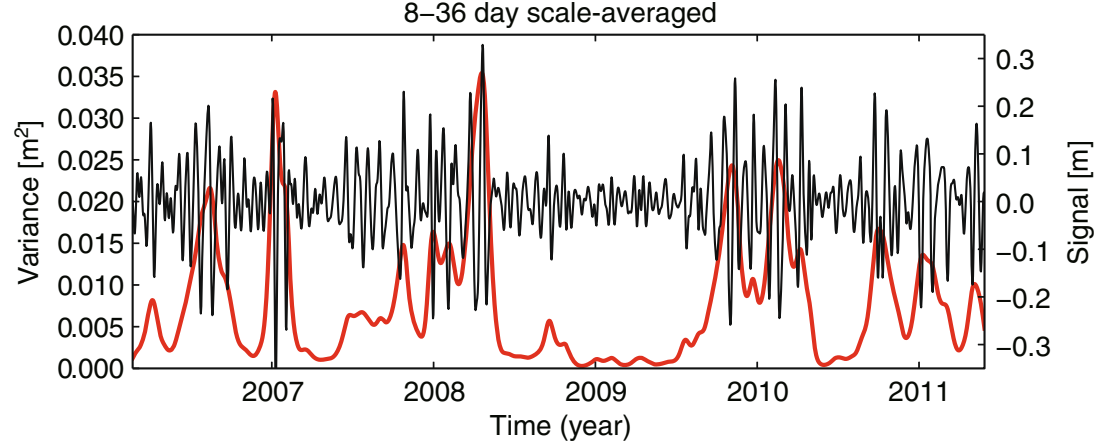

certain period band, we can reconstruct the time series of SSH fluctuations (in meters) in the corresponding period band. The solid black line in Fig. 4 is the reconstructed time series using the wavelet coefficients in the 8- to 36-day period band. This is equivalent to the 8 - to 36 -day band-pass-filtered time series of the original time series (Fig. 2a). In this paper, the bandpass-filtered fluctuation of the original time series using the wavelet method is referred to as the "signal" of the period band.

Throughout this paper, we use the method described above to obtain the variance and signal of the 8- to 36-day periods from the original time series in the region shown in Fig. 1. Among the available data in the JCOPE2 reanalysis, we start with the wavelet analysis for $\mathrm{SSH}$, which reflects the ocean dynamics beneath the surface. Later in the discussion, we use velocity, temperature, and salinity (for density) data. Although we applied the wavelet analysis to the data of the whole time period (from February 23, 2006 to May 31, 2011), we only describe the data from April 15, 2006 to April 14, 2011 in order to minimize the influence of the data edges (indicated by the cross-hatched regions in Fig. 2b).

\section{Horizontal distribution and its relation to the Kuroshio path}

In this section, we describe the horizontal distribution of the 8to 36-day fluctuations. The color shading in Fig. 5 shows the horizontal maps of variances of the 8- to 36-day period band, time-averaged over the whole analysis time period (from April 15, 2006 to April 14, 2011). This figure was obtained by applying the wavelet analysis at every model grid point. The contours in Fig. 5 show the unfiltered SSH time-averaged over the same period. By geostrophy, the contours indicate the direction of flow of ocean currents, and the narrow spacing between the lines indicates strong Kuroshio flow in this region. The 8- to 36-day fluctuations are active in the region where the Kuroshio flows. A high variance spreads from east to west between $33^{\circ}$ and $34^{\circ} \mathrm{N}$. The relatively low variance near Cape Shionomisaki is amplified toward the high variance around the area west of the Izu Ridge.
In order to study how short-term fluctuations respond to shifts in the Kuroshio path, we first define the Kuroshio path. Looking at the relationship between the surface velocity and $\mathrm{SSH}$ in the JCOPE2 reanalysis, we found that the SSH isoline of $0.1 \mathrm{~m}$ is located around the maximum of the surface velocity (not shown). Therefore, we define the SSH isoline of $0.1 \mathrm{~m}$ as the Kuroshio path. Similar definitions using SSH isolines were used by Qiu and Chen (2005) and Sugimoto and Hanawa (2011). Because we are interested in the response of the short-term fluctuations to the low-frequency change of the background flow, we used a low-pass-filtered SSH to define the Kuroshio path. We again used the wavelet method and obtained a 90-day low-pass-filtered signal of SSH by reconstructing the signal from the wavelet coefficients for periods longer than 90 days.

After defining the Kuroshio path from the low-pass-filtered $\mathrm{SSH}$, the distance of the Kuroshio path from the coast was measured using the latitude of the Kuroshio path at $138.5^{\circ} \mathrm{E}$. Figure 6 shows the time series of the latitude of the Kuroshio path at $138.5^{\circ} \mathrm{E}$. High (low) latitude indicates that the Kuroshio takes a nearshore (offshore) path. From this latitude of the Kuroshio path, we defined the two typical paths of the

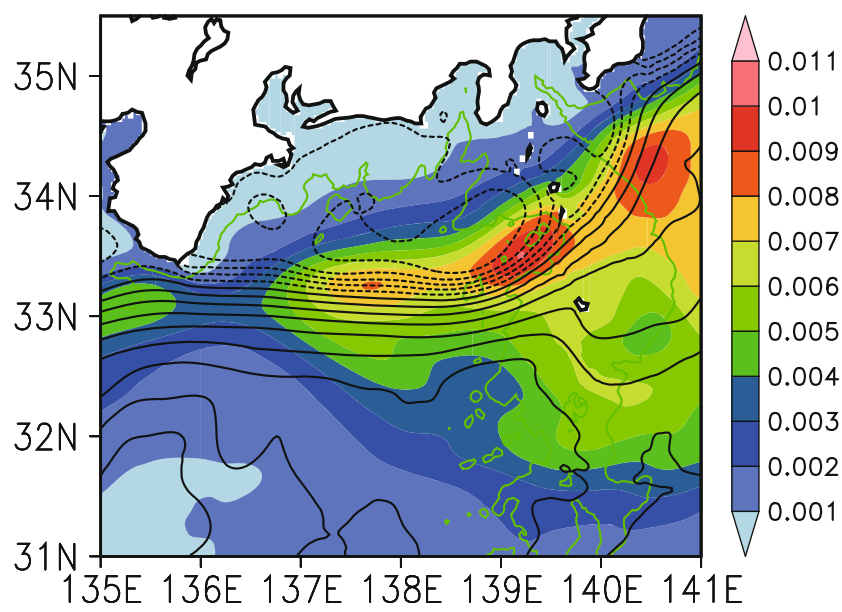

Fig. 5 Horizontal distributions of the wavelet variance of SSH for the 8to 36-day period band (color shadings; square meter) averaged over the whole analysis time period (from April 15, 2006 to April 14, 2011). Contours show the unfiltered SSH (meter) averaged over the same period. Green line shows the 1,500-m isodepth contour 


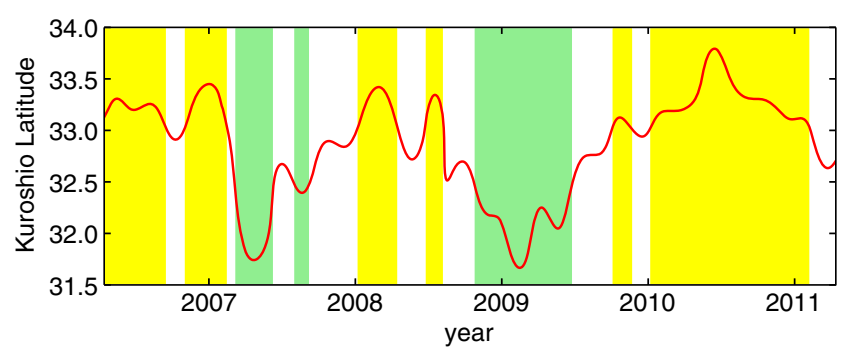

Fig. 6 Time series of the latitude of the Kuroshio path at $138.5^{\circ} \mathrm{E}$. The NP and OP periods are shaded yellow and light green, respectively

Kuroshio as follows: the nearshore path is located north of $33^{\circ} \mathrm{N}$ (hereafter NP; shaded yellow in Fig. 6) and the offshore path is located south of $32.5^{\circ} \mathrm{N}$ (hereafter OP; shaded light green in Fig. 6). The results presented in this paper were not sensitive to small changes in these choices (not shown). The numbers of days during which NP and OP occur are 875 (48\%) and $389(21 \%)$, respectively, out of the total 1,826 days from April 15, 2006 to April 14, 2011, respectively.

Using these definitions, we made composites of 8- to 36day fluctuations for the two typical paths by averaging the daily data belonging to NP and OP. Figure 7a shows the composite map during NP. Figure $7 b$, on the other hand, shows the composite map during OP. The contours in the figures are composites of the 90-day low-pass-filtered SSH. Therefore, the contours show where the background Kuroshio flows, and the thick solid line (0.1-m isoline) represents the Kuroshio path. As intended by our definition, the contours in panels $a$ and $b$ of Fig. 7 show the nearshore path and the offshore path, respectively. Color shadings in panels a and $\mathrm{b}$ of Fig. 7 indicate the variances of the 8- to 36-day fluctuations during NP and OP, respectively. These figures indicate that the area of high variance of the 8- to 36-day fluctuations is located along the Kuroshio path, and it moves with the Kuroshio path. The peak variance during NP is higher than that during OP.

The variance of the 8- to 36-day fluctuations in the Enshunada Sea (around $137.5^{\circ} \mathrm{E}, 34^{\circ} \mathrm{N}$ ) in Fig. $7 \mathrm{~b}$ during OP is not low compared with the variance during NP in Fig. 7a, although the region is far from the Kuroshio path during OP as indicated by the thick black line in Fig. 7b. The variance of the 8- to 36day fluctuations in the Enshu-nada Sea during the OP is also due to the effect of the S-shaped meander, which is indicated by the arrow in Fig. 7b. This is discussed in the next section.

\section{Typical structures}

First, we discuss typical structures during NP. Figure 8 shows a typical time sequence of the development of the 8- to 36-day fluctuations when the Kuroshio Current took a nearshore path. The color shadings in Fig. 8a, c, e, g are wavelet variances of SSH every 5 days starting on December 27, 2006. The high variances are detected by the wavelet method around the mean

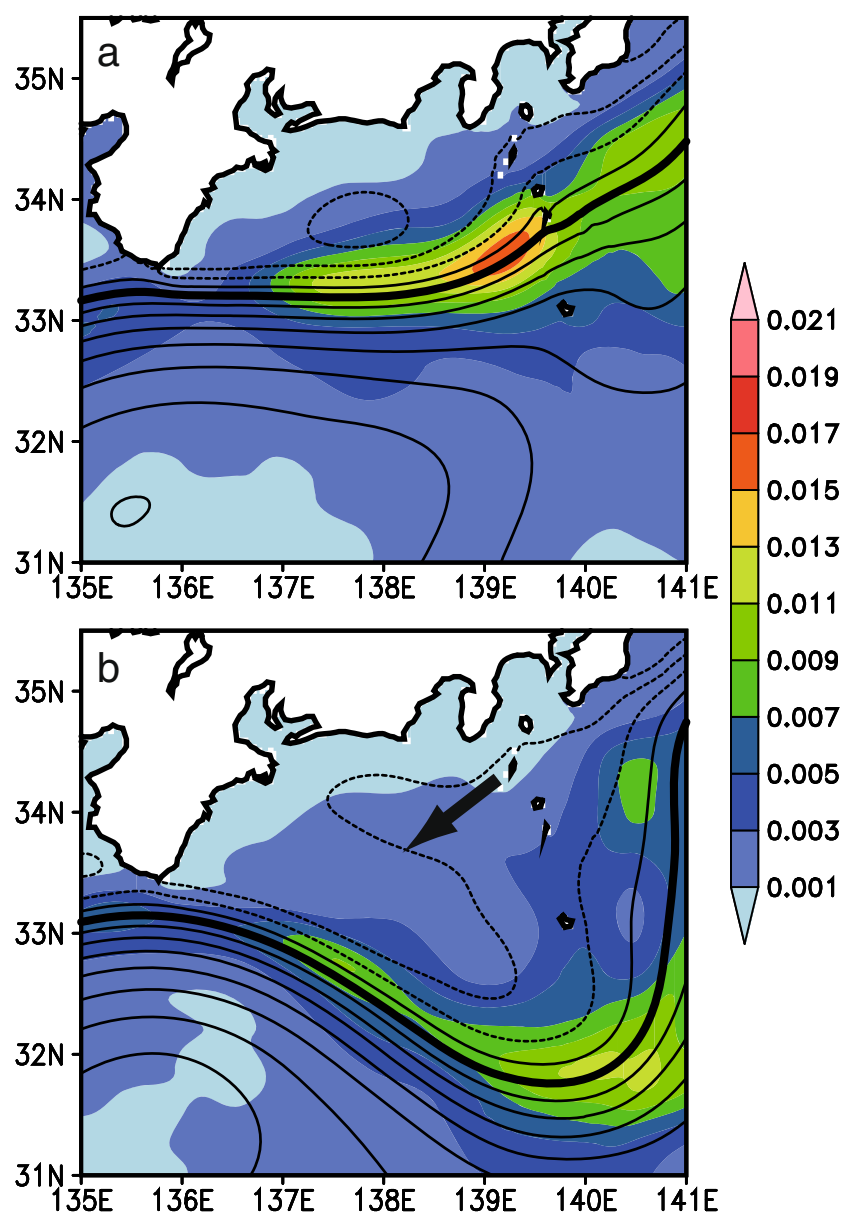

Fig. 7 Composite maps of the variance (color shadings, square meter) and 90-day low-pass-filtered SSH (contour, meter) for the 8- to 36-day fluctuations. Thick contour is the 0.1-m contour of 90-day low-passfiltered SSH which represents the Kuroshio path. a During NP. b During OP. The arrows in b points to the contour of the vestige of the S-shaped SSH meander

positions of the Kuroshio path (thick dashed lines), which are indicated by the 90-day low-pass-filtered $\mathrm{SSH}$ isoline of $0.1 \mathrm{~m}$. The relatively low variance near Cape Shionomisaki increases downstream around the Izu Ridge. The variance also increases with time, as shown in Fig. 8a-g.

The color shadings in Fig. $8 \mathrm{~b}, \mathrm{~d}, \mathrm{f}, \mathrm{h}$ are wavelet signals of $\mathrm{SSH}$ corresponding to the variances in Fig. 8a, c, e, g. An undulating pattern emerges in these signals. The signals of SSH along the slowly varying Kuroshio path (dashed line in Fig. 8) are also plotted in Fig. 9. The value was obtained by averaging the signals from $20 \mathrm{~km}$ inshore to $20 \mathrm{~km}$ offshore along the cross-path axis (Appendix B). Changing $20 \mathrm{~km}$ into 40 or $0 \mathrm{~km}$, for example, does not change the qualitative results in Fig. 9. In Figs. 8 and 9a, a typical low SSH signal and a high SSH signal are tracked by the blue and red arrows, respectively.

Each signal in Figs. 8 and 9a propagates downstream (eastward) with intensified value. Corresponding to the signals, the snapshots of the Kuroshio path (thick solid line in Fig. 8), indicated by the unfiltered $\mathrm{SSH}$ isoline of $0.1 \mathrm{~m}$ on 
Fig. 8 A typical time sequence of the development of the 8- to 36day fluctuations. Color shading and thin contours in $\mathbf{a}$ and $\mathbf{b}$ are the wavelet variance (square meter) and signal (meter) of SSH on December 27, 2006,

respectively. Black solid (dashed) line represents the Kuroshio path shown by the non-filtered (90-day low-pass-filtered) $0.1-\mathrm{m}$ isoline of SSH. c, d On January 1, 2007. e, f On January 6, 2007. g, h On January 11, 2007. In b, d, f, and $\mathbf{h}$, a low and a high SSH signal are tracked by a blue and a red arrow, respectively
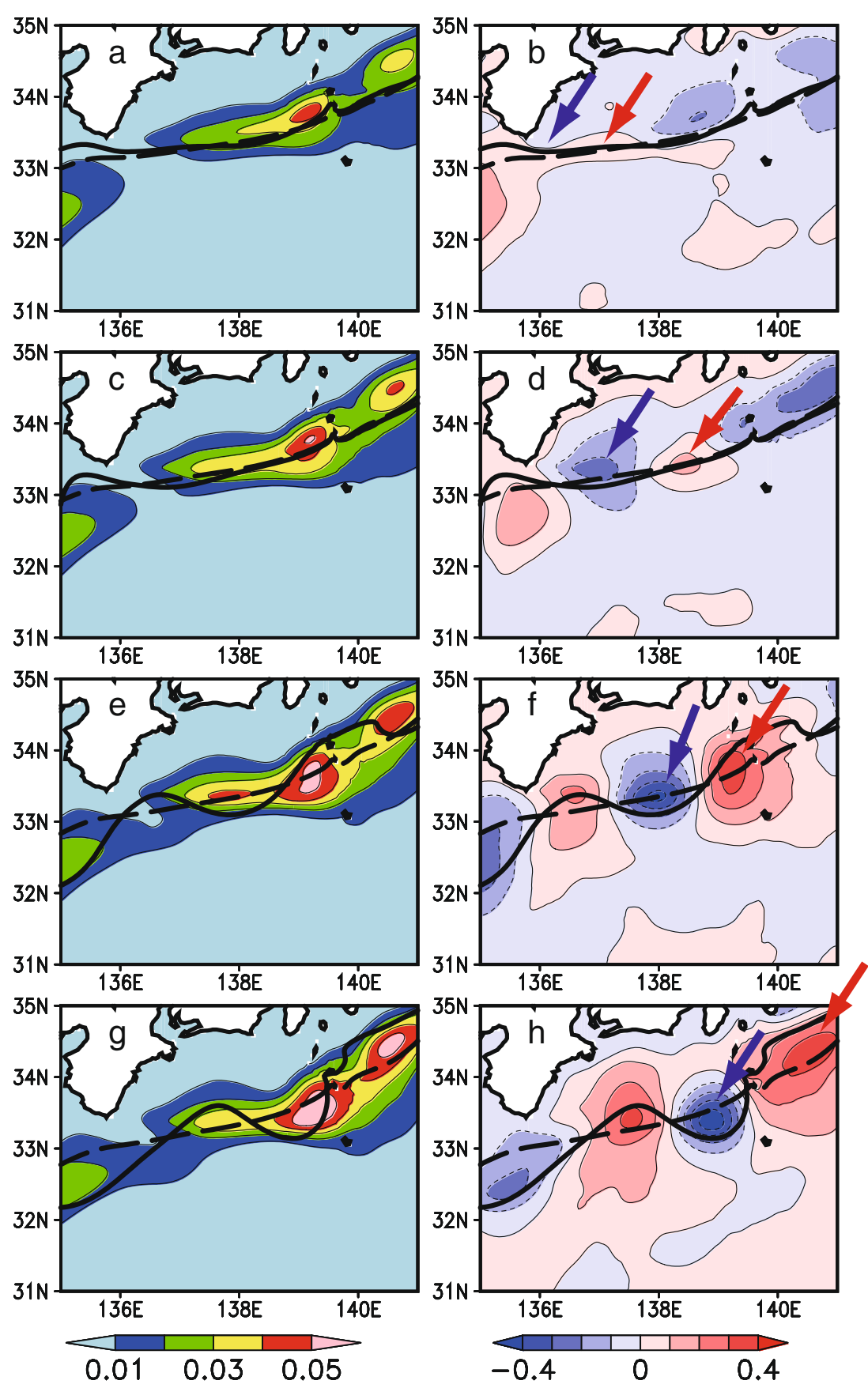

each day, reveal an undulating pattern relative to the mean Kuroshio path (thick dashed line in Fig. 8). The path of the Kuroshio becomes more undulating, as shown in Fig. 8b-h, corresponding to the increase in variance with time (Fig. 8ag). Figure 9 clearly shows that the signals grow downstream of Cape Shionomisaki.

Although a relatively high variance is detected at $135^{\circ} \mathrm{E}$, $32.5^{\circ} \mathrm{N}$, the smooth connection toward the downstream region is hampered by the presence of Cape Shionomisaki when the Kuroshio path (thick black solid line) is located close to Cape Shionomisaki. The gap is indicated by the low variance near Cape Shionomisaki in Fig. 8a-c. Propagation of the signals from the upstream region is weak, as shown in Fig. 8b, d, and the first half of Fig. 9a. As the Kuroshio path shifts farther offshore from Cape Shionomisaki, the connection from the upstream to the downstream regions becomes smoother. The variance near Cape Shionomisaki is higher (Fig. 8e, g) than before. The propagation of a positive (red) signal of SSH passes Cape Shionomisaki in Fig. 8f, h, and the second half in Fig. 9a.

Figure 10 shows the velocities and temperatures during the same period and for the same dates as in Fig. 8. During this period, the 90-day low-pass-filtered absolute velocity (the shading in the left panels of Fig. 10) was strong in the downstream side of Cape Shionomisaki. Corresponding to 


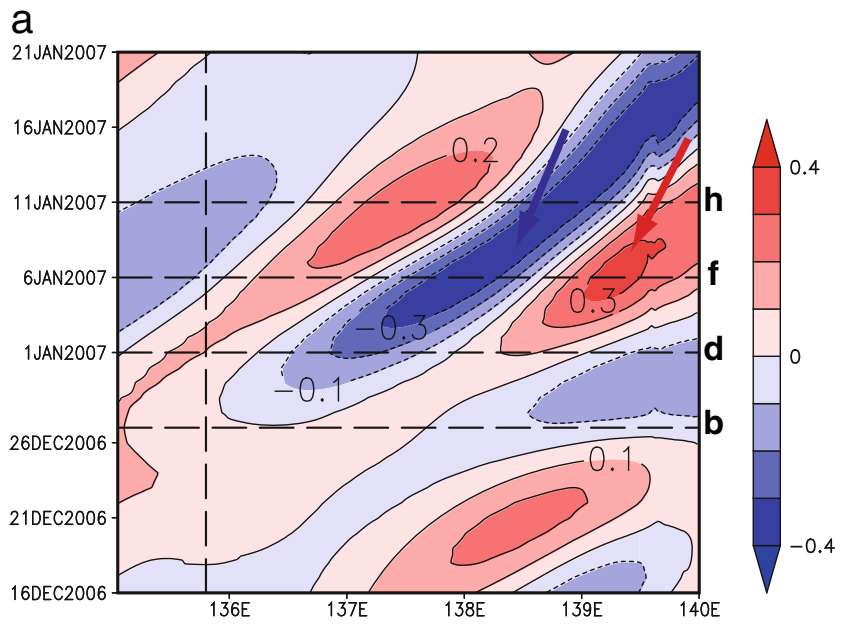

b

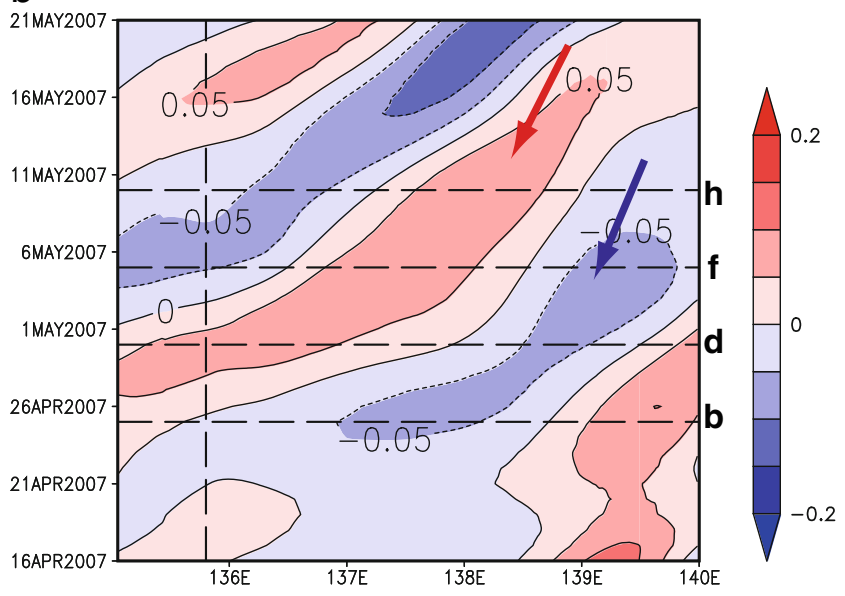

Fig. 9 a Along-path-time diagram of the signal of SSH (color shading and contour, meter) from December 16, 2006 to January, 21 2007. The signal was averaged from $20 \mathrm{~km}$ inshore to $20 \mathrm{~km}$ offshore along the crosspath axis. The horizontal dashed lines correspond to the dates in Fig. 8b, d, $\mathrm{f}, \mathrm{h}$, respectively. The vertical dashed line corresponds to the longitude of Cape Shionomisaki. The low and high SSH tracked by the arrows in Fig. 8 are pointed by a blue and a red arrow, respectively. b Along-path-time diagram for April 16, 2007 to May 21, 2007. The horizontal dashed lines correspond to the dates in Fig. 11b, d, f, h, respectively. The low and high SSH tracked by the arrows in Fig. 11 are pointed by a blue and a red arrow, respectively. Everything else is the same as in a

the strong velocity, the meridional temperature gradient was sharp on the inshore side of the area with the strong velocity (not shown). Miyama and Miyazawa (2013) described the structure of the strong velocity downstream of Cape Shionomisaki and the accompanying sharp meridional temperature gradient on the inshore side of the velocity. They argued that the strong velocity is a manifestation of the Kuroshio acceleration at Cape Shionomisaki, which often occurs when the Kuroshio takes the nearshore path. The relationship between the Kuroshio acceleration and the 8- to 36-day fluctuations is discussed in Section 6.

Velocity signals (the vectors in the right panels of Fig. 10) are consistent with the SSH signals in Fig. 8: anticyclonic (cyclonic) circulations around high (low) SSHs. Temperature signals (color shadings in the right panels of Fig. 10) also displayed a corresponding undulating pattern. The signals were strong on the inshore side of the Kuroshio path where the background temperature gradient was sharp. While the variance of the 8- to 36-day fluctuations increase with time (color shadings in Fig. 8a, c, e, g), the background velocity decreased (color shadings in Fig. 10a, c, e, g).

Next, we discuss typical structures during OP. Figures 11 and 12 show a typical time sequence of the development of the 8- to 36-day fluctuations when the Kuroshio Current takes an offshore path (every 5 days starting on April 25, 2007). Signals of SSH along the Kuroshio path are plotted in Fig. 9b. During this period, the variance (color shadings in the left panels of Fig. 11), signals of the SSH (color shadings in the right panels of Fig. 11), and signals of velocities and temperatures (vectors and color shadings in the right panels of Fig. 13) appeared around the offshore path of the Kuroshio (thick dashed line). Although the patterns appear to be similar to those during the nearshore path, the amplitudes in Figs. 11, 12, and 9b are small compared with those in Figs. 8, 10, and $9 \mathrm{a}$ during the nearshore path period. Note that the contour levels in Figs. 8 and 11, Figs. 10 and 12, and Fig. 9a, b are different. The background velocity (color shadings in the left panels of Fig. 12) does not show the strong Kuroshio acceleration that is apparent in Fig 10a. The gradient of the values between the upstream and downstream of Cape Shionomisaki along the Kuroshio path appears to be smaller (Fig. 9b) than that during the nearshore path (Fig. 9a) described above.

A unique feature during the offshore period in Figs. 11 and 12 is that there were westward-propagating signals around $34^{\circ} \mathrm{N}$ toward the Enshu-nada Sea. A typical high SSH and a corresponding high SST are tracked by the green arrows in Figs. 11 and 12, respectively. These westward signals happened because a westward-flowing branch of the Kuroshio intruded into the Enshu-nada Sea when the S-shaped meander of the Kuroshio around the Izu Ridge was enhanced (the thick solid lines in Figs. 11 and 12). To show how far the Kuroshio path intrudes into the S-shaped meander, a non-filtered $-0.25-\mathrm{m}$ isoline of SSH (red curve) is added to Figs. 11 and 12. Observations of the intrusion of water from the Kuroshio by the westward branch into the coastal areas of the Kumano-nada Sea and the Enshunada Sea with a dominant period of about 20 days have been reported (Kimura and Sugimoto 2000). It should be noted that the emergence of the S-shaped meander itself was not the result of the 8- to 36-day fluctuations. The enhanced S-shape (black solid contour relative to black dashed line) continued throughout Fig. 11, indicating that the emergence of the S-shaped meander was caused by lower frequency fluctuations than the 8- to 36-day fluctuations. The emergence of the S-shaped meander is the result of 40- to 80-day fluctuations (not shown), as observed by Kasai et al. (1993) and Takahashi et al. (2011).

Finally, we statistically confirm the typical undulating pattern described above. Figure 13a shows the horizontal distribution of the correlation (contour) and the regression (color 
Fig. 10 Color shadings and thin contours in the left panels show the 90-day low-pass-filtered absolute velocities (meter/ second). Vectors and color shadings in the right panels are 8to 36-day wavelet band-passfiltered velocities (meter/second) and temperatures (degree Celsius) at 50-m depth. Everything else is the same as in Fig. 8
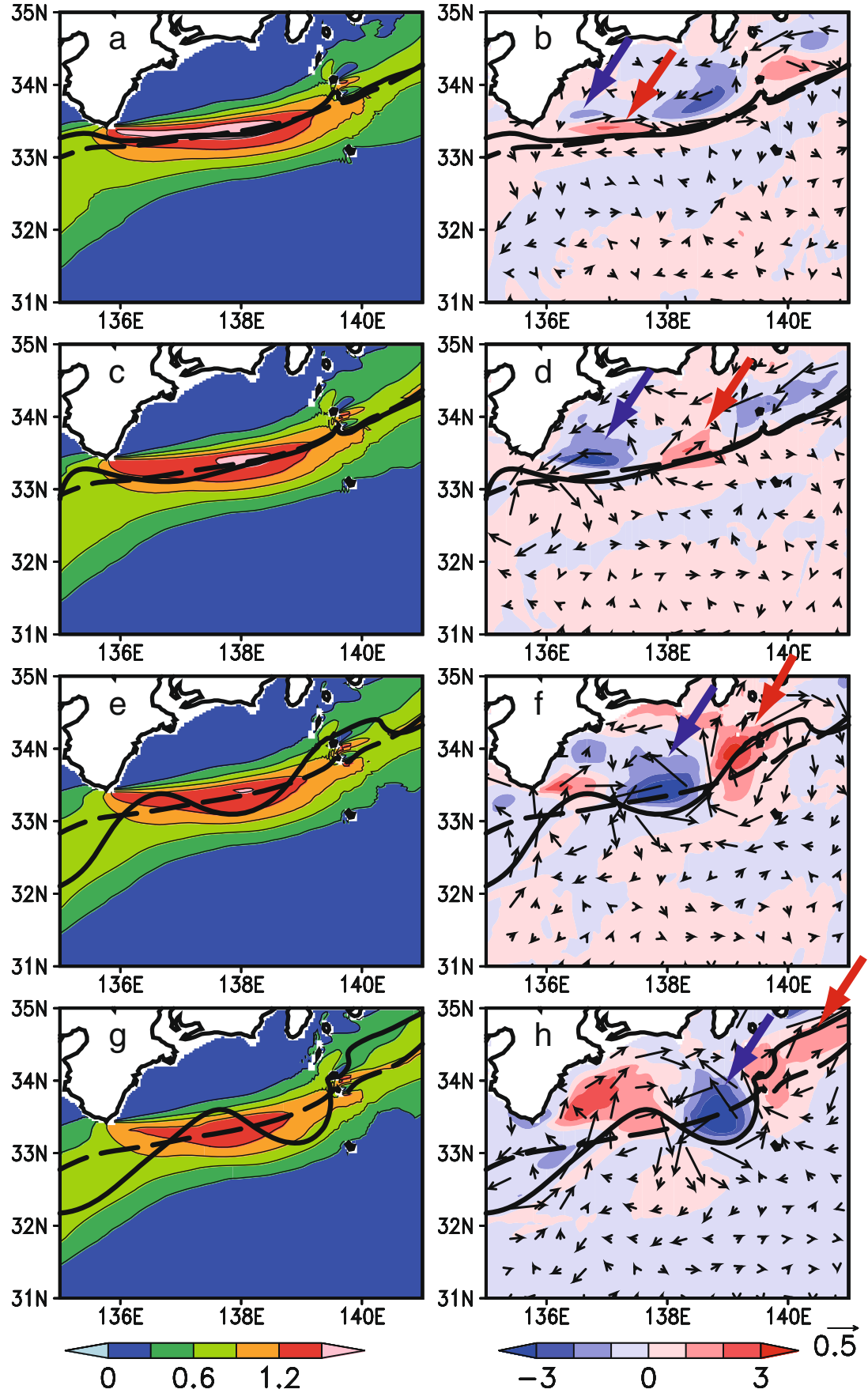

shadings; meter/meter) of the SSH signal (meter) at each point to the $\mathrm{SSH}$ signal (meter) at point $\mathrm{A}\left(139.2^{\circ} \mathrm{E}, 33.5^{\circ} \mathrm{N}\right)$, which is close to the maximum variance shown in Fig. $7 \mathrm{a}$, using the daily data during NP. As shown in the typical pattern described in the preceding subsection, undulating patterns of plus and minus values appear along the Kuroshio path (thick black solid line). The correlation toward the upstream of Cape Shionomisaki quickly decays. The distance between points A $\left(139.2^{\circ} \mathrm{E}, 33.5^{\circ} \mathrm{N}\right)$ and $\mathrm{A}^{\prime}\left(136^{\circ} \mathrm{E}, 33.2^{\circ} \mathrm{N}\right)$ in Fig. 13a corresponds to a wavelength about $300 \mathrm{~km}(299 \mathrm{~km})$. The lag correlation between the signals of points $\mathrm{A}$ and $\mathrm{A}^{\prime}$ becomes maximum (0.35) when $\mathrm{A}^{\prime}$ leads $\mathrm{A}$ by 21 days. Therefore, this statistical estimate shows that the wave period is 21 days, and the downstream phase speed is about $14 \mathrm{~km} /$ day $(0.16 \mathrm{~m} / \mathrm{s})$.

Figure $13 \mathrm{~b}$ shows the horizontal distribution of the correlation (contour) and the regression (color shadings; meter/ meter) of the SSH signal (meter) at each point to the SSH signal at point $\mathrm{B}\left(139.5^{\circ} \mathrm{E}, 31.8^{\circ} \mathrm{N}\right)$, which is close to the maximum variance shown in Fig. 7 b, using the daily data during OP. This figure also shows the undulating patterns of plus and minus values appearing along the Kuroshio path during OP. The continuation of the undulating pattern toward 
Fig. 11 Same as Fig. 8 except that $\mathbf{a}, \mathbf{b}$ on April 25, 2007; $\mathbf{c}, \mathbf{d}$ on April 30, 2007; e, f on May 5, 2007; and $\mathbf{g , ~ h}$ on May 10, 2007. Additional red lines are the nonfiltered $-0.25-\mathrm{m}$ isoline of $\mathrm{SSH}$. Additional green arrows track a westward-moving high SSH
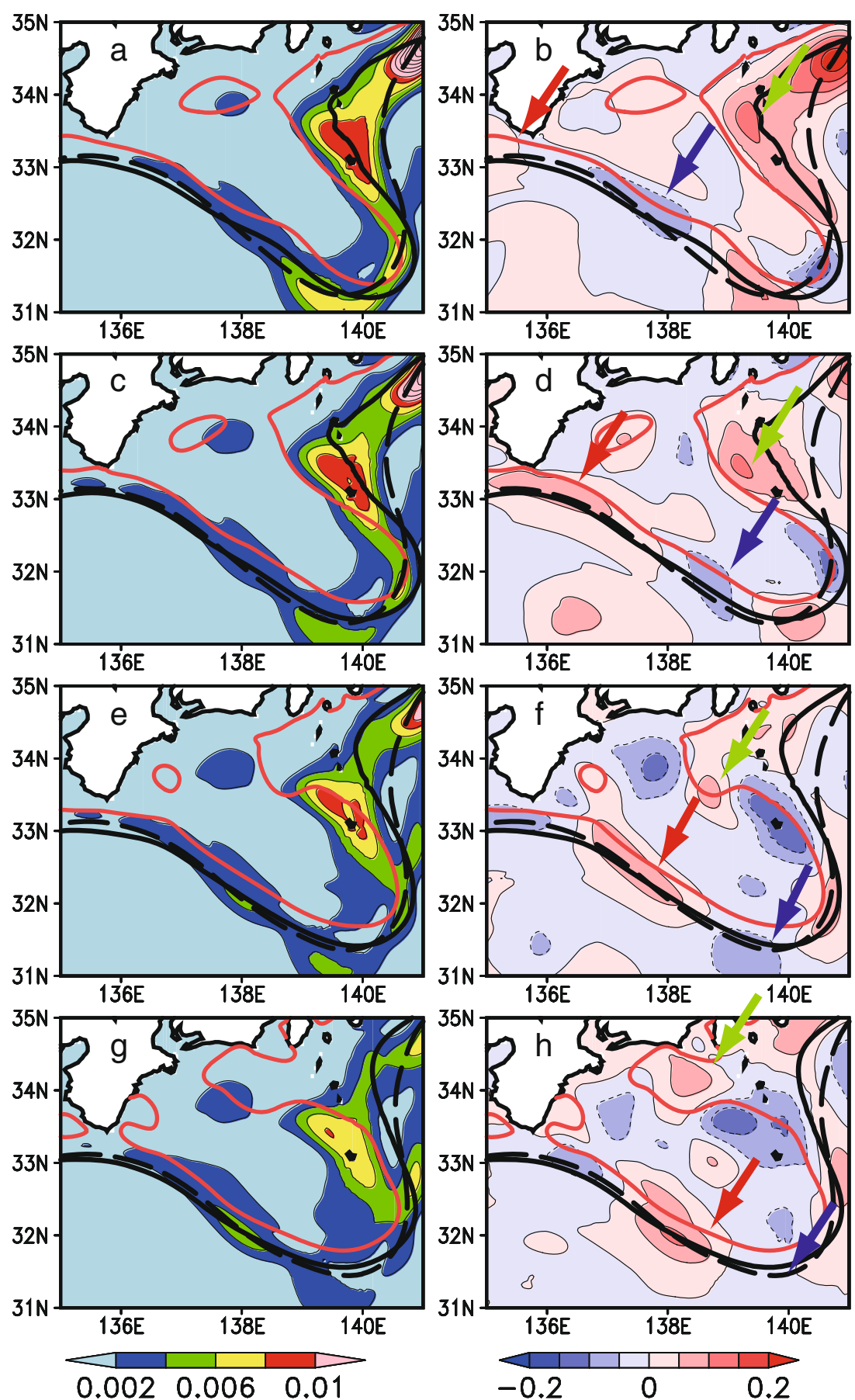

the upstream of Cape Shionomisaki is somewhat clearer than that during NP, but it is still small. The distance between points $\mathrm{B}\left(139.5^{\circ} \mathrm{E}, 31.8^{\circ} \mathrm{N}\right)$ and $\mathrm{B}^{\prime}\left(136.5^{\circ} \mathrm{E}, 33.05^{\circ} \mathrm{N}\right)$ in Fig. $13 \mathrm{~b}$ corresponds to a wavelength of $314 \mathrm{~km}$. Although the estimate of the wavelength during OP is slightly longer than that during NP, the significance of this difference is not certain because the current method is a rough estimate based on a pointwise correlation. The lag correlation between the signals of points B and B' becomes maximum (0.19) when B' leads $\mathrm{B}$ by 19 days. Therefore, this statistical estimate shows that the wave period is 19 days and that the downstream phase speed is about $17 \mathrm{~km} /$ day $(0.20 \mathrm{~m} / \mathrm{s})$.

\section{Vertical structure}

In order to reveal the vertical structure of the 8- to 36-day fluctuations, the color shadings in Fig. 14 show vertical sections of the composites of the variances of the zonal velocity (square meter/square second) plus the variance of the 
Fig. 12 Same as Fig. 10 except that $\mathbf{a}, \mathbf{b}$ on April 25, 2007; c, d on April 30, 2007; e, f on May 5, 2007; and $\mathbf{g , ~ h}$ on May 10, 2007. Newly added red lines are the non-filtered $-0.25-\mathrm{m}$ isoline of $\mathrm{SSH}$. Newly added green arrows track a westward-moving high SST

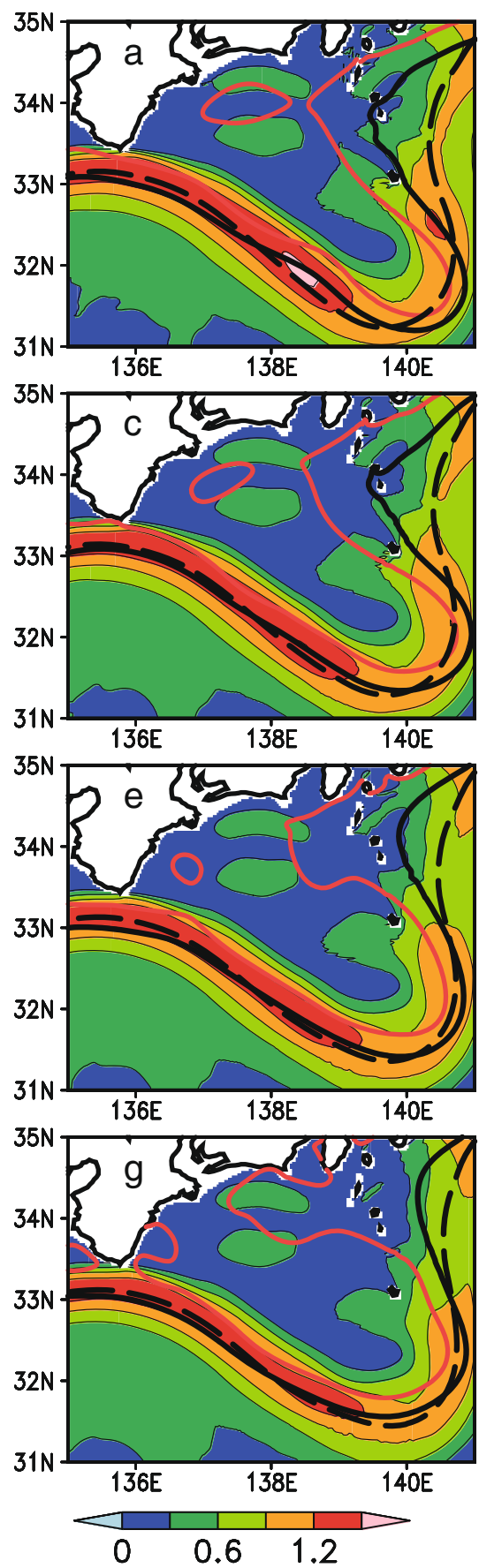

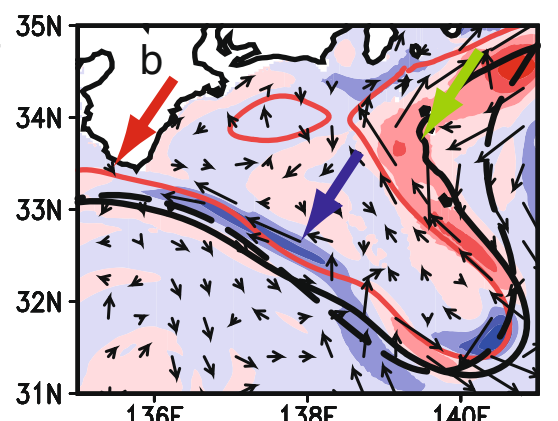
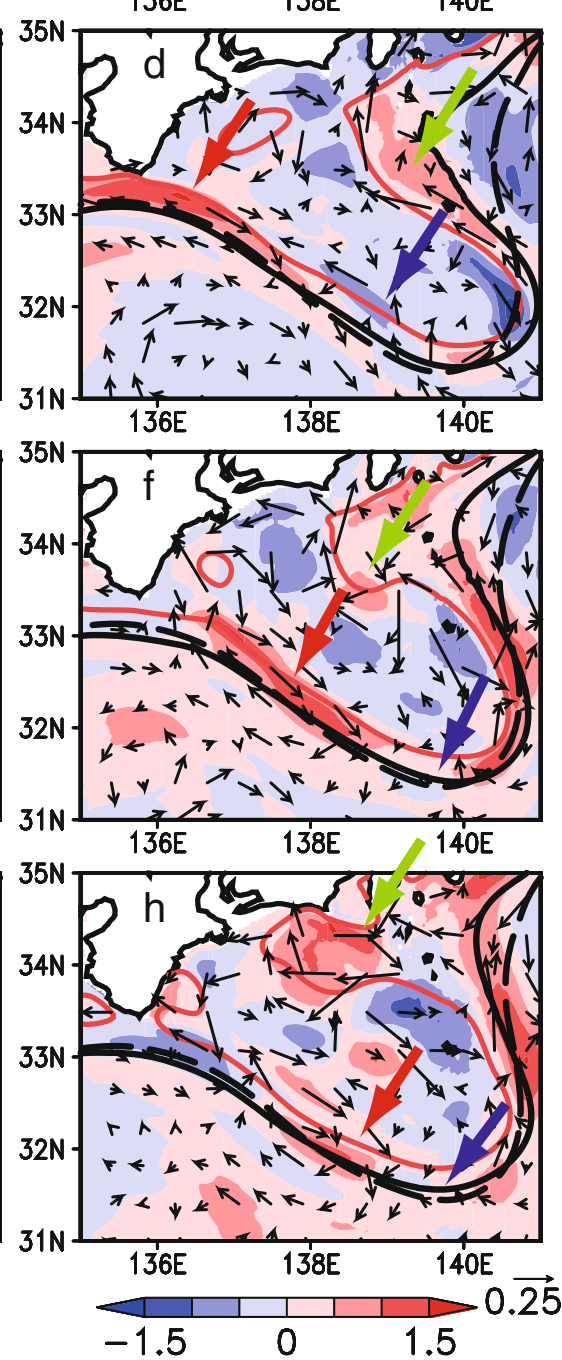

meridional velocity (square meter/sqaure second), which is equivalent to the eddy kinetic energy. Variances of the velocity (color shadings) along $137^{\circ} \mathrm{E}$ shown in both Fig. 14a during $\mathrm{NP}$ and Fig. 14b during OP show that the variance is highest at the surface on the inshore (northward) side of the background velocity maximum (90-day low-pass-filtered; contours; meter/ second). The high variance coincides with the place where the velocity gradient is steep. Slight enhancements of the variances on the offshore (southward) side of the velocity maximum are also found. They coincide with the place of another sharp velocity gradient. Following the background velocities, the variances decay and tilt southward with depth. Because the background velocity is higher during NP than during OP, the variance is higher during NP than during OP.

While the features of the variance along $137^{\circ} \mathrm{E}$ continue downstream along $138^{\circ} \mathrm{E}$ (Fig. $14 \mathrm{c}$, d), the variances along $138^{\circ} \mathrm{E}$ are more enhanced, and the local maxima of the offshore (southward) side of the background velocity maximum are less clear than along $137^{\circ} \mathrm{E}$.

We also show that the composites in the Kuroshio path coordinate system in panels e and $\mathrm{f}$ of Fig. 14 corresponding the panels $\mathrm{c}$ and d of Fig. 14, respectively. The results in the 


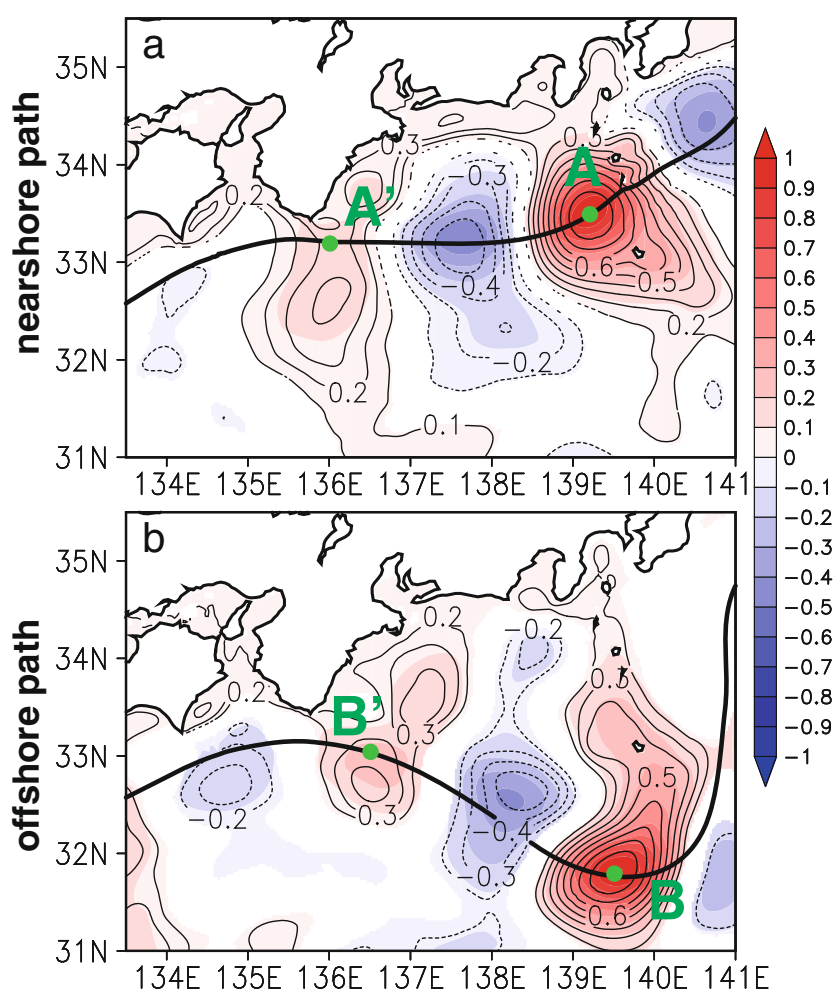

Fig. 13 a Horizontal distribution of the correlation (contour) and the regression (color shading; meter/meter) of the SSH signal of the 8- to 36day fluctuations to the $\mathrm{SSH}$ signal at point $A\left(139.2^{\circ} \mathrm{E}, 33.5^{\circ} \mathrm{N}\right)$, which is around the maximum variance of Fig. 7a, using only daily data during NP. b Same as a but to the signal at point $B\left(139.5^{\circ} \mathrm{E}, 31.8^{\circ} \mathrm{N}\right)$, which is around the maximum in the variance of Fig. $7 \mathrm{~b}$, using only daily data during OP. The significant regions with $99 \%$ confidence level are plotted

Kuroshio path coordinate system is presented because the composites in the fixed geographical coordinate system might cause artificial diffusion when the latitude of the flow varies in time (Halkin and Rossby 1985; Howe et al. 2009). The results in the Kuroshio path coordinate system in Fig. 14f shows stronger background velocity (dashed contour) and higher velocity variance (color shading and thin contour; square meter/square second) than the composites in the geographical coordinate system in Fig. 14d during the OP. However, Fig. 14e, f still shows that the background velocity and the velocity variance are larger during NP than during OP.

\section{Relation to the Kuroshio acceleration}

In Section 4, we mentioned the Kuroshio acceleration at Cape Shionomisaki is a typical occurrence in the 8- to 36-day fluctuations during the nearshore path. Miyama and Miyazawa (2013) studied the sudden acceleration of the Kuroshio jet that often appears off Cape Shionomisaki when the Kuroshio flows near the cape. The velocity discontinuity is accompanied by cold water outcropping on the inshore side downstream of Cape Shionomisaki. Miyama and Miyazawa
(2013) proposed that the dynamics of the Kuroshio acceleration are a manifestation of a hydraulic control at Cape Shionomisaki when the Kuroshio approaches the coast. Kawabe (1990) found that, in order to provide a theoretical explanation of their paths, the nearshore non-large-meander path requires a larger Kuroshio acceleration than the offshore non-large-meander path. Because the 8- to 36-day fluctuations also become active during the nearshore path, we discuss the relationship between the Kuroshio acceleration and the 8- to 36-day fluctuations.

The red solid line in Fig. 15 shows the Kuroshio acceleration at Cape Shionomisaki determined using the same definition used by Miyama and Miyazawa (2013): the zonal velocity difference between $135.4^{\circ} \mathrm{E}, 33.4^{\circ} \mathrm{N}$ and $136.2^{\circ} \mathrm{E}$, $33.4^{\circ} \mathrm{N}$ at $10-\mathrm{m}$ depth. However, we used the 90-day lowpass-filtered velocity instead of the daily or the monthly values used in Miyama and Miyazawa (2013) because we are interested in the response of the short-term fluctuations to the low-frequency change in the background flow. Because of the cutoff period of the low-pass filter, the Kuroshio acceleration in Fig. 15 in this paper is smaller than that shown in Fig. 10 in Miyama and Miyazawa (2013).

As also reported in Miyama and Miyazawa (2013), the Kuroshio acceleration (red solid line in Fig. 15) shows a high correlation (0.80) with the latitude of the Kuroshio at $138.5^{\circ} \mathrm{E}$ (black line in Fig. 15; the same as the red line in Fig. 6), despite the absence of the Kuroshio large meander in the dataset and the different definition of the Kuroshio path compared with that used by Miyama and Miyazawa (2013). In Miyama and Miyazawa (2013), the latitude of the Kuroshio is defined by the location of maximum velocity between $136^{\circ} \mathrm{E}$ and $140^{\circ} \mathrm{E}$, $30.5-35^{\circ} \mathrm{E}$ at $10-\mathrm{m}$ depth. The high correlation between the Kuroshio acceleration and the Kuroshio latitude means that the Kuroshio acceleration (red solid line in Fig. 15) is stronger during the nearshore path (shaded yellow) than the offshore path (shaded lightgreen) as Kawabe (1990) has shown. Miyama and Miyazawa (2013) showed that the velocity on the downstream side of Cape Shionomisaki is controlled by the Kuroshio acceleration. In fact, the zonal velocity on the downstream side of Cape Shionomisaki at $136.2,33.4^{\circ} \mathrm{N}$ (red dashed line in Fig. 15) shows a high correlation (0.86) with the Kuroshio acceleration (red solid line in Fig. 15).

Figure 16 shows the horizontal map of the lagged correlation coefficient (contour) and the regression (color shading; square meter/(meter/second)) between the Kuroshio acceleration (solid line in Fig. 16; meter/second) and the variance of the 8- to 36-day SSH fluctuation (square meter) when the Kuroshio acceleration leads the variance by 30 days. The lead time was used so that the highest correlation appears in Fig. 16. The high positive correlation and regression region collocates with the active region of the 8- to 36-day fluctuations in Fig. 5, and especially with the active region during NP in Fig. 7a. The negative correlation and regression in Fig. 16 
Fig. 14 Color shadings and thin contours show the vertical sections of the composites of the variances of the zonal velocity plus the variance of the meridional velocity (square meter/square second). Dashed contours at $0.6,1.0$, and $1.4 \mathrm{~m} / \mathrm{s}$ show 90-day low-pass-filtered absolute velocities (meter/ second). Vertical axis is depth (meter). Horizontal axis is latitude for $\mathbf{a}, \mathbf{b}, \mathbf{c}$, and $\mathbf{d}$. Horizontal axis is the cross-path axis (kilometer) for e and f. a Along $137^{\circ} \mathrm{E}$ during NP. b Along $137^{\circ} \mathrm{E}$ during OP. c Along $138^{\circ} \mathrm{E}$ during NP. d Along $138^{\circ} \mathrm{E}$ during OP. e, f The composites during NP and OP in the Kuroshio path coordinate at $138^{\circ} \mathrm{E}$, respectively
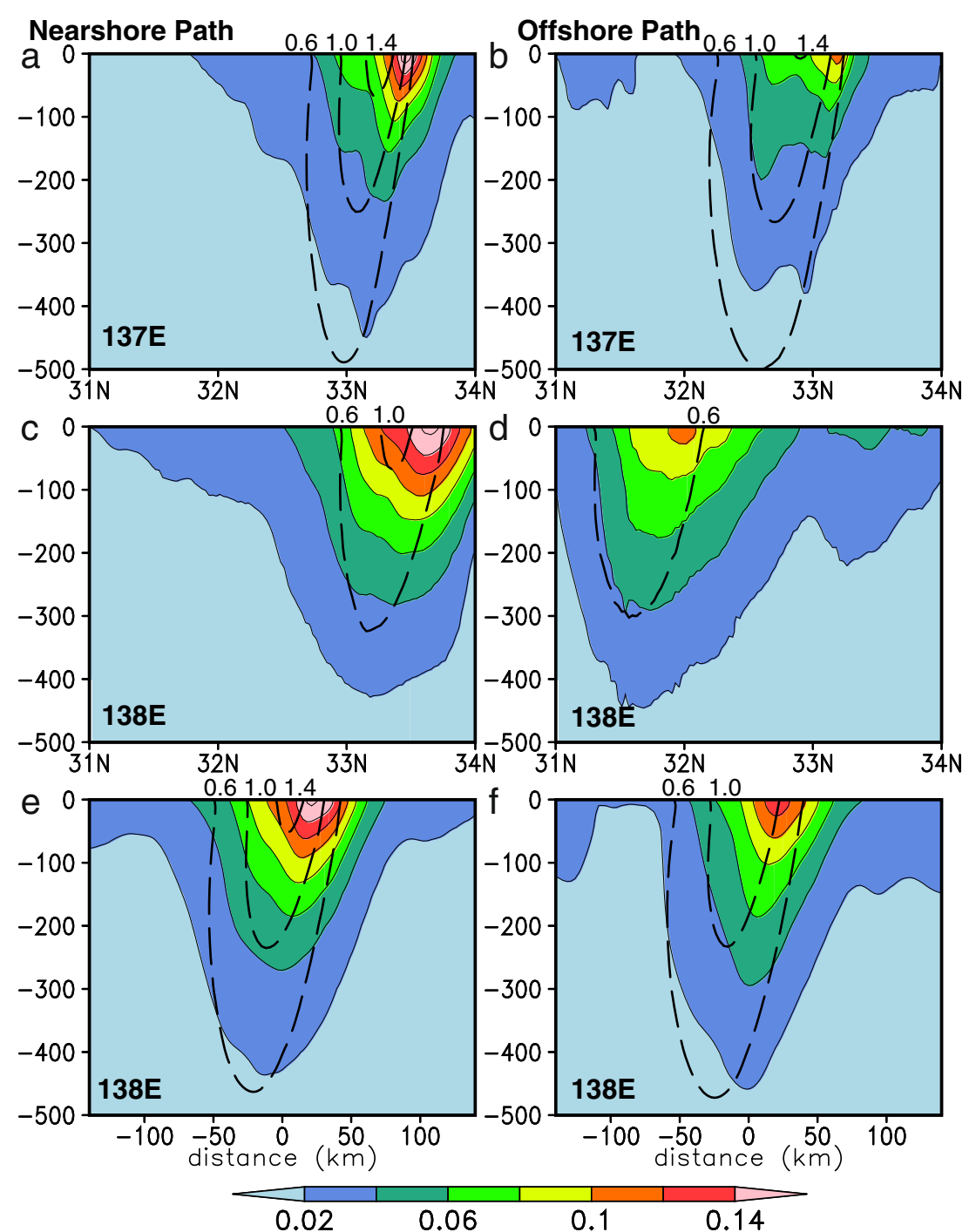

appears near $140^{\circ} \mathrm{E}, 32^{\circ} \mathrm{N}$. This coincides with the active region of the 8- to 36-day fluctuations during OP (Fig. 7b). This negative relation appears because the Kuroshio acceleration tends to be weak during OP. The negative value of the regression (minimum about -0.012 ) is weaker than the positive value (maximum about 0.018), which reflects that the 8- to 36-day fluctuations are more active during NP than OP. These results suggest that the Kuroshio acceleration has a correlation with the amplitude of the 8- to 36-day fluctuations.

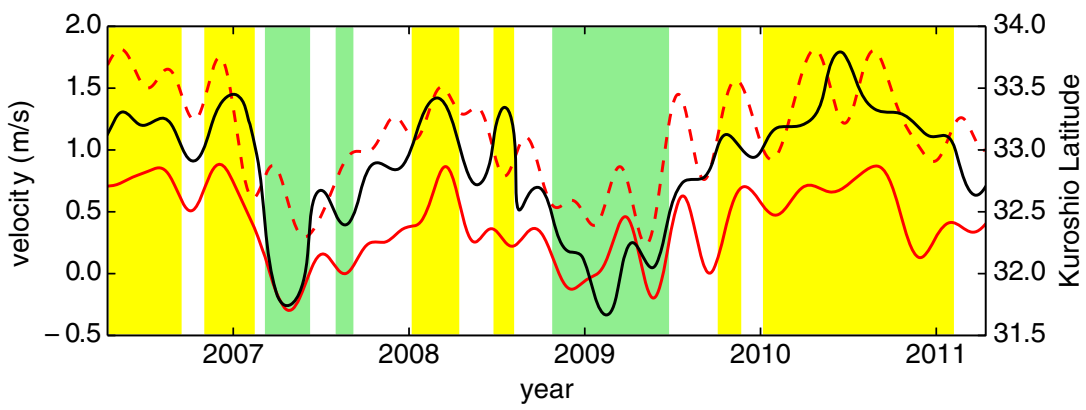

Fig. 15 Time series of the zonal velocity increase from $135.4^{\circ} \mathrm{E}, 33.4^{\circ} \mathrm{N}$ to $136.2,33.4^{\circ} \mathrm{N}$ (red solid line; meter/second; axis on the left) and the velocity at $136.2^{\circ} \mathrm{E}, 33.4^{\circ} \mathrm{N}$ (dashed line; meter/second; axis on the left). The 90-day low-pass-filtered zonal velocity at 10-m depth was used. The black solid line is the latitude of the Kuroshio path (the same as the red line in Fig. 6; axis on the right). The NP and OP periods are shaded yellow and light green, respectively 


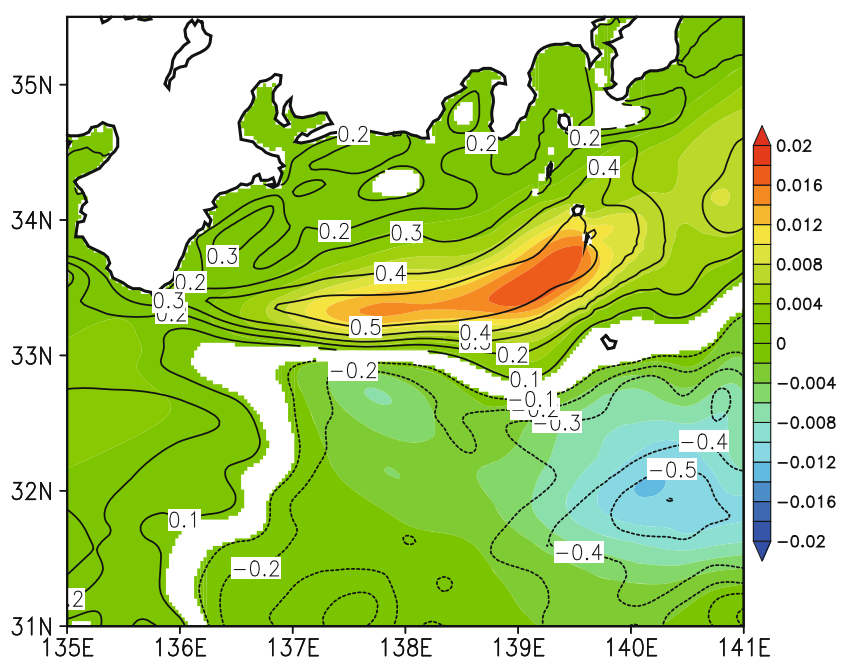

Fig. 16 Horizontal map of the correlation coefficient (contour) and the regression (color shading and thin contours; square meter/(meter/second)) between the variance of the 8- to 36-day SSH fluctuation (square meter) and the Kuroshio acceleration (the solid line in Fig. 17; meter/ second) using the daily data from April 15, 2006 to April 14, 2011 when the Kuroshio acceleration leads the variance by 30 days. The significant regions with $99 \%$ confidence level are plotted

Because the above results imply that the 8- to 36-day fluctuations are more active when the background velocity is stronger, it can be hypothesized that the fluctuations are the result of instability. To examine the degree of instability, we analyzed the local energetics in the same way as in Miyazawa et al. (2004).

The local energy transfer from mean kinetic energy to eddy kinetic energy is expressed as follows (Wells et al. 2000):

$K=-\left[\overline{u^{\prime} u^{\prime}} \frac{\partial \bar{u}}{\partial x}+\overline{u^{\prime} v^{\prime}}\left(\frac{\partial \bar{u}}{\partial y}+\frac{\partial \bar{v}}{\partial x}\right)+\overline{v^{\prime} v^{\prime}} \frac{\partial \bar{v}}{\partial y}\right]$,

where $u(v)$ denotes the eastward (northward) perturbed velocity, and $x(y)$ denotes the zonal (meridional) direction. The prime and overbar quantities represent fluctuations and time means, respectively. When $K$ is positive, it can be interpreted that the barotropic instability generates disturbances.

Similarly, the energy transfer from mean potential energy to eddy kinetic energy is judged by the following term:

$P=-g \frac{\overline{u^{\prime} \rho^{\prime}}(\partial \bar{\rho} / \partial x)+\overline{v^{\prime} \rho^{\prime}}(\partial \bar{\rho} / \partial y)}{\rho_{0} d \rho_{\mathrm{b}}(z) / d z}$,

where $g$ is the gravity acceleration; $\rho, \rho_{0}$, and $\rho_{b}(z)$ are density, reference density, and background density, respectively; and z denotes vertical direction. When $P$ is positive, it can be interpreted that the baroclinic instability generates disturbances. A part of $P$ is transformed into eddy kinetic energy through the buoyancy term, $B=-g \overline{\rho^{\prime} w^{\prime}}$, where $w$ is the perturbed vertical velocity. However, the complicated distribution of vertical velocity owing to rough bottom topography prevents us from obtaining a meaningful view from the plot of $B$ (Wells et al. 2000; Miyazawa et al. 2004).

Here, the wavelet 8- to 36-day band-pass-filtered signals are used for the prime quantities. The wavelet 90-day lowpass filter is used to obtain the overbar quantities.

Figure 17a shows the vertical section of composites of the energy conversion term $K$ during NP along the across-path coordinate at $137^{\circ} \mathrm{E}$. High $K$ values (color shadings) appear where the horizontal velocity gradient is sharp on both sides of the velocity (contour) maximum at the surface, and is especially high on the inshore (northward) side of the velocity maximum. Figure $17 \mathrm{~b}$ shows the vertical section of composites of the energy conversion term $P$ (color shadings) during NP along the across-path coordinate along $137^{\circ} \mathrm{E}$. A high $P$ appears where the horizontal temperature (contour) gradient is sharp on the inshore (northward) side of the velocity maximum at the subsurface. The location is where the vertical gradient of the velocity in Fig. 17a is strong from the thermal wind relationship. These high $K$ and $P$ values indicate that both barotropic and baroclinic instabilities are favorable for generating disturbances. This is consistent with the existence of the high variance of the velocity on the inshore (northward) side of the velocity maximum in Fig. 14a.

Figure $17 \mathrm{c}, \mathrm{d}$ show that high $K$ and $P$ values (color shadings) also appear in the composites during OP. There are still high values on the inshore side of the velocity maximum. However, the $K$ and $P$ values are much smaller than those during NP (Fig. 17a, b). This reflects a weaker velocity and accompanying temperature gradient during OP (contours in Fig. 17c, d) than during NP (contours in Fig. 17a, b).

Figure 18a shows the barotropic conversion term $K$ during NP in the geographical horizontal map at the surface $(10-\mathrm{m}$ depth), which is the depth where the value of $K$ is highest (Fig. 17a). Figure $18 \mathrm{~b}$ shows the baroclinic conversion term $P$ during NP at 100-m depth, which is the depth where the value of $P$ is highest (Fig. 17b). The $K$ and $P$ values are high around the Kuroshio path (thick black solid line), especially on the inshore side of the path. The high values stretch downstream from Cape Shionomisaki. This is because the Kuroshio acceleration at Cape Shionomisaki generates a strong velocity gradient and temperature gradient, especially on the inshore side of the Kuroshio Current (Miyama and Miyazawa 2013). The high positive energy conversion rates on the downstream side of Cape Shionomisaki explain why the 8- to 36-day fluctuations are enhanced from near Cape Shionomisaki toward the downstream region around the Izu Ridge.

Figure 18c, d during OP corresponds to Fig. 18a, b during NP. The energy conversion terms in Fig. 18c, d are small compared with those in Fig. 18a, b because the Kuroshio acceleration is small during OP. However, the values of $K$ and $P$ downstream of Cape Shionomisaki all along the Kuroshio path are still relatively higher than those of the 
Fig. 17 Vertical sections of composites of the energy conversion terms (color shadings and thin contours; $10^{-6}$ square meter/cubic second) in the Kuroshio path coordinate at $137^{\circ} \mathrm{E}$. a $K$ during NP. b $P$ during NP. c $K$ during OP. d $P$ during OP. Dashed contours at $0.6,1.0$, and $1.4 \mathrm{~m} / \mathrm{s}$ in $\mathbf{a}$ and $\mathbf{c}$ are the background (90-day low-passfiltered) absolute velocity (meter/ second) during NP and OP, respectively. Dashed contours in $\mathbf{b}$ and $\mathbf{d}$ are the background (90day low-pass-filtered) temperature (degree Celsius) during NP and OP, respectively. The contour interval for the temperatures is $2^{\circ} \mathrm{C}$. Vertical axis is depth (meter). Horizontal axis is the cross-path axis (kilometer)
Barotoropic term $K$
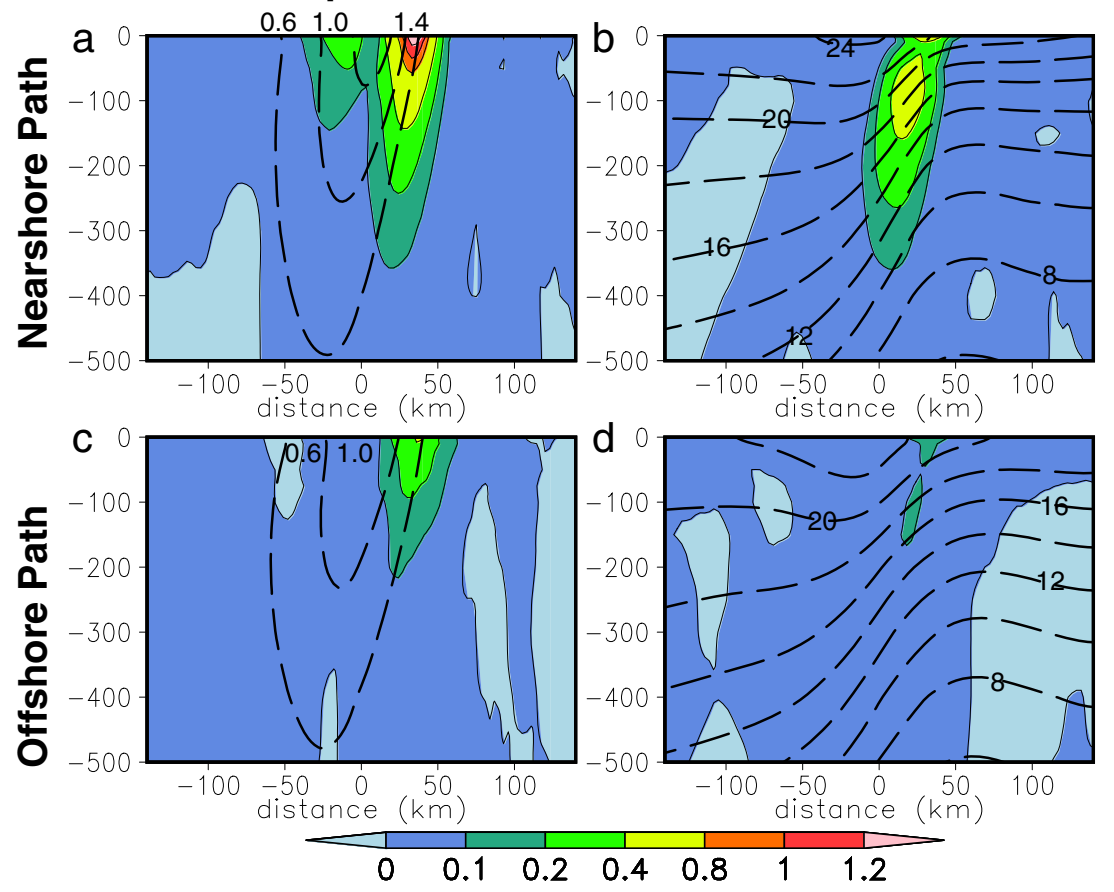

surrounding regions. This explains the downstream enhancement of the 8- to 36-day fluctuations during OP, albeit weaker than NP.

The relationship of the Kuroshio acceleration with the energy conversion terms can also be confirmed in the time series of $K$ and $P$ integrated over $136-139^{\circ} \mathrm{E}, 31-35^{\circ} \mathrm{N}$ from 0 to 1,000-m depth (Fig. 19). The Kuroshio acceleration (meter/ second; black line in Fig. 19, same as the red line in Fig. 15) shows positive correlations with the integrated $K$ value (me$\operatorname{ter}^{5} /$ second $^{3}$; red line in Fig. 19), highest coefficient (0.50) when the acceleration leads by 2 days, and with the integrated $P\left(\right.$ meter $^{5} /$ second $^{3}$; blue line in Fig. 19), highest coefficient (0.61) when the acceleration leads by 23 days, respectively. The reason for the different lead times for $K$ and $P$ is unknown, and will be a subject of a future study. The integrated $K$ value is overall larger than the integrated $P$ value, suggesting the relative importance of the barotropic instability. The ratio of $K$ to $P$ does not show any significant correlation to the Kuroshio acceleration (not shown). Therefore, the Kuroshio acceleration does not seem to affect the ratio of $K$ to $P$.
Fig. 18 Horizontal maps of composites of the energy conversion terms (color shadings and thin contours; $10^{-6}$ square meter/cubic second). a $K$ at $10-\mathrm{m}$ depth during NP. b $P$ at $100-\mathrm{m}$ depth during NP. c $K$ at $10-\mathrm{m}$ depth during OP. d $P$ at $100-\mathrm{m}$ depth during OP. Thick solid lines are Kuroshio paths (90-day lowpass-filtered 0.1-m SSH contours)

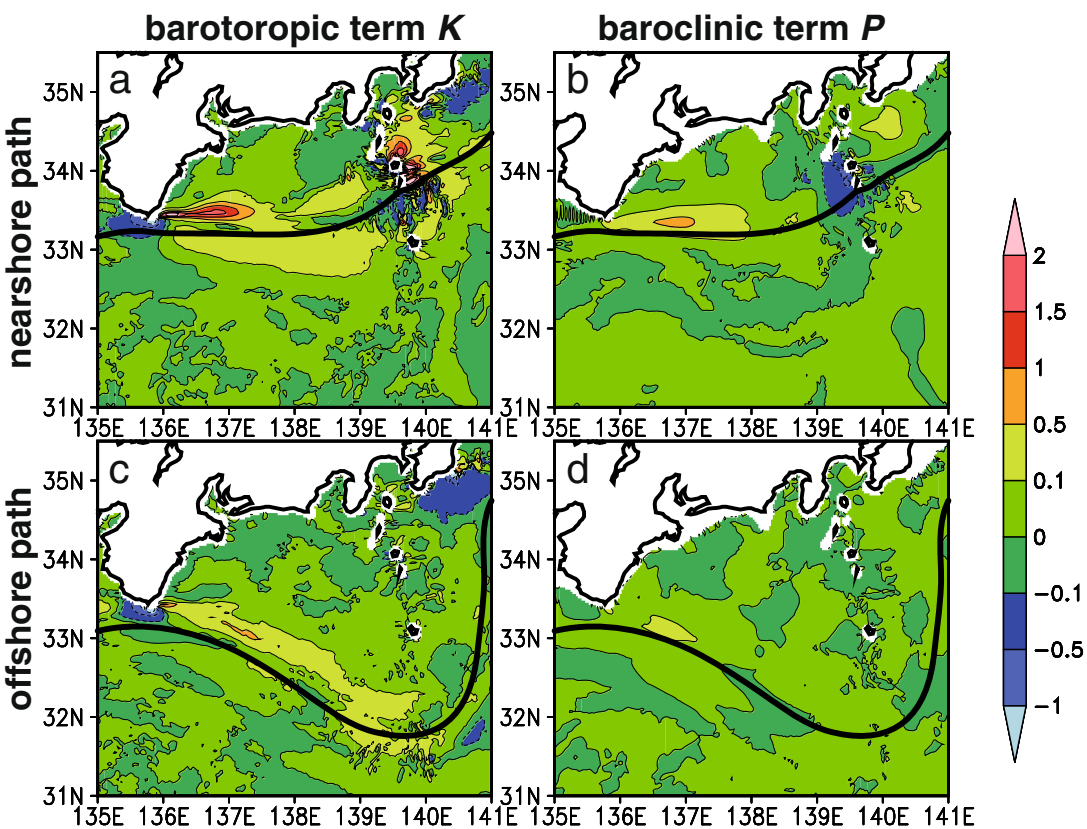




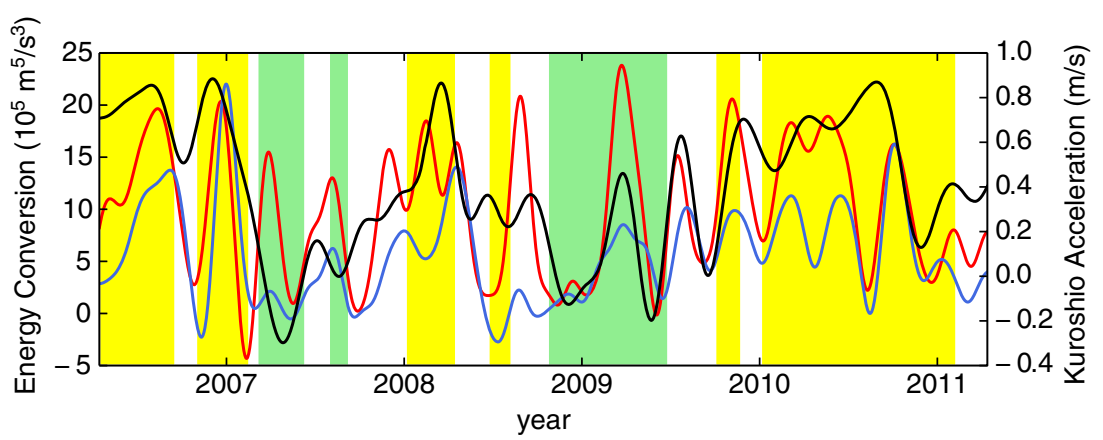

Fig. 19 Time series of the energy conversion terms $K$ (red line) and $P$ (blue line) integrated over $136-139^{\circ} \mathrm{E}, 31-35^{\circ} \mathrm{N}$ from 0 to $1,000-\mathrm{m}$ depth $\left(10^{5}\right.$ meter $^{5} /$ second $^{3}$; axis on the left $)$. The black line is the Kuroshio

Figure 18 also shows that the energy conversion terms are negative on the upstream side of Cape Shionomisaki, indicating that the eddy energy is absorbed into the mean energy. This explains why the variances near Cape Shionomisaki decrease in Fig. 5.

\section{Summary and discussion}

This study describes 8- to 36-day fluctuations south of Japan using the JCOPE2 reanalysis data with a horizontal resolution of $1 / 36^{\circ}$. To detect the short-term fluctuations, we applied wavelet analysis. The amplitude of the 8-to 36-day fluctuations increases eastward from Cape Shionomisaki toward downstream around the Izu Ridge. The fluctuations of the 8to 36-day period band are more active during the period of the nearshore non-large-meander path of the Kuroshio than during the period of the offshore non-large-meander path. The fluctuations of the 8- to 36-day period band appear as frontal waves on the Kuroshio Current. The waves have a wavelength of about $300 \mathrm{~km}$, and the signals propagate eastward.

We found a relationship between the Kuroshio acceleration at Cape Shionomisaki and the amplitude of the 8- to 36-day period band. An analysis of energy conversion terms shows that both barotropic and baroclinic instabilities are important for generating eddies corresponding to the 8- to 36-day fluctuations. If the Kuroshio acceleration is a super critical flow resulting from hydraulic control, as proposed by Miyama and Miyazawa (2013), generation of a disturbance can be interpreted as a kind of hydraulic jump. A hydraulic jump is an abrupt transition process, which is often accompanied by turbulence and undulating patterns, from an unstable supercritical flow to a subcritical flow (Pratt and Whitehead 2007).

Because the Kuroshio acceleration produces a strong velocity shear and a sharp temperature gradient on the inshore side of the velocity maximum, the variance of the velocity is strong on the inshore side of the velocity maximum. As the velocity core shifts southward with depth, the high variance of the velocity moves southward with depth. The variance of the acceleration (meter/second; axis on the right, same as the solid red line in Fig. 15). The NP and OP periods are shaded yellow and light green, respectively

$\mathrm{SSH}$, which reflects the underlying physics is high around the Kuroshio path. Because the Kuroshio acceleration is strong during the nearshore path, the variance of the 8- to 36-day fluctuations is higher during the nearshore path than during the offshore path.

The signals upstream of Cape Shionomisaki do not show a high correlation with the signals downstream. From the local minimum around Cape Shionomisaki, the variance is enhanced toward the downstream region around the Izu Ridge. The reason for the small upstream influence is partly because the condition at Cape Shionomisaki is adverse to eddy growth (negative values of the conversion terms in Fig. 18), and partly because the local growth of disturbances downstream diminishes the upstream influences. Because these factors are relatively small along the path during the offshore path, the correlation between upstream and downstream is slightly higher than during the nearshore path. In the Gulf Stream, Savidge (2004) found that high-frequency (3- to 8-day) fluctuations decay almost completely downstream of Cape Hatteras, with growth in the longer period (30- to 120-day) fluctuations. Comparing similarities and differences between the Kuroshio and the Gulf Stream is an interesting topic.

Because of the local enhancement of the disturbance, we focused on the region between Cape Shionomisaki and the Izu Ridge in this study and did not discuss fluctuations upstream of Cape Shionomisaki. A small upstream influence in the variance does not exclude the possibility that signals from upstream sometimes flow downstream of Cape Shionomisaki and/or that small activities upstream can be a trigger of instability on the downstream side. The influence of the fluctuations upstream of Cape Shionomisaki will be further investigated in a future study.

Another interesting subject for a future study would be to determine how the short-term fluctuations in this study affect fluctuations further downstream. Just as the Kuroshio path affects the fluctuations in this study, Sugimoto and Hanawa (2011) showed that the Kuroshio path also affects short-term fluctuations in the Kuroshio Extension. Unfortunately, we cannot discuss the relationship between the short-term 
fluctuations in this study and eddy activities downstream because the data used in this study do not extend past the eastern boundary at $142^{\circ} \mathrm{E}$.

While some studies have combined the fluctuations of periods of around 10 and 20-30 days (Itoh and Sugimoto 2008), other studies treated them separately (Kimura and Sugimoto 1993; Hinata et al. 2008; Ramp et al. 2008). When the 8- to 36-day fluctuations are separated into 8- to 16-day and 16- to 36-day fluctuations, the horizontal distributions of the variance of both frequency bands show nearshore peaks similar to Fig. 5 (not shown). The time series of the variance of both the 8- to 16-day and 16- to 36-day period bands averaged over $137-140^{\circ} \mathrm{E}, 33-34^{\circ} \mathrm{N}$ around the peak region in Fig. 5 show similar timings of peaks (Fig. 20) although they are not exactly the same. The correlation between the two curves in Fig. 20 is 0.58 (the correlation becomes maximum at 0 -day lag). Figure 20 also shows that the variance of the 8- to 16-day fluctuations (black curve) is overall much smaller than that of the 16- to 36-day fluctuations (red curve). Excluding the 8- to 16-day fluctuations from 8- to 36-day fluctuations does not affect the conclusions presented in this paper (not shown). Therefore, there was no particular reason to treat 8- to 16-day fluctuations separately in this study. It should be noted, however, that the fluctuations with periods of around 10 days might be only minimally resolved by data of 1-day intervals. Therefore, we cannot deny the possibility that the variance of the 8- to 16-day fluctuations is underestimated. We might revisit this issue on these frequencies in a future study using a different dataset and/or methodology.

An interesting question is why disturbances of periods of around 8- to 36-days are generated. Frontal waves of similar frequencies have been reported in other coastal areas in Japan: in the East China Sea (Sugimoto et al. 1988; Qiu et al. 1990; James et al. 1999), in the Tokara Strait (Qiu et al. 1990; Maeda et al. 1993; Feng et al. 2000), south of Shikoku (Awaji et al. 1991), near the separation point of the Kuroshio to the Kuroshio Extension (Itoh and Sugimoto 2008), and in the Kuroshio Extension (Tracey et al. 2012). Frontal wave disturbances have been also found in the Gulf Stream (Lee and Atkinson 1983; Tracey and Watts 1986; Oey 1988; Savidge 2004). Itoh and Sugimoto (2008) successfully applied the analytical model of baroclinic instability by Pedlosky (1987)

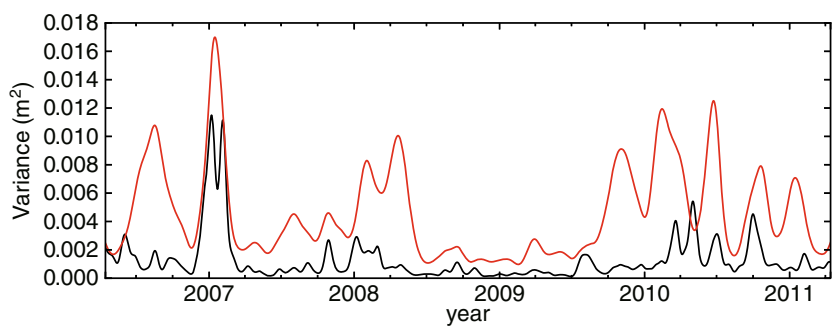

Fig. 20 Time series of the variances of the 8- to 16-day period band (black curve) and of the 16- to 36-day period band (red curve) averaged over $137-140^{\circ} \mathrm{E}, 33-34^{\circ} \mathrm{N}$ to the variability of the Kuroshio near the separation point from the western boundary, and they also discussed similar fluctuations in other regions of the Kuroshio. However, to explain the variability in this paper, the theory of pure baroclinic instability is insufficient because the analysis of the energy conversion terms shows that barotropic instability is also important. Using an instability analysis and a theoretical model, we will seek factors to determine the time and spatial scale of frontal waves in future studies.

Discussion of the 40- to 80-day fluctuations will be addressed in another paper. In contrast to the 8- to 36-day fluctuations, the peak variance of the 40- to 80-day fluctuations during OP is higher than that during NP (Appendix A). Because the peak region of 40 - to 80 -day fluctuations overlaps with the peak region of 8- to 36-day fluctuations on the downstream side of the Izu Ridge, the interaction between them might be important here. A full understanding of the short-term fluctuations on the downstream side of the Izu Ridge is beyond the scope of this study and needs further investigation.

We identified the properties of short-term fluctuations in the form of frontal waves and determined their relationship with the background velocity and the Kuroshio path. This knowledge will be beneficial for predicting when short-term fluctuations become active. As mentioned in the Section 1, the frontal waves of the Kuroshio Current affect biological activities and fisheries. Therefore, a better understanding of these short-term fluctuations will be important for the management of ecological environments.

Acknowledgments This work is a part of the Japan Coastal Ocean Predictability Experiment (JCOPE) promoted by the Japan Agency for Marine-Earth Science and Technology (JAMSTEC). Tomohiko Tsunoda conducted the calculation of the JCOPE2 with 1/36 resolution. We would like to thank Sergey M. Varlamov, Takuji Waseda, Humio Mitsudera, and Sourav Sil for their helpful discussions. The authors would like to thank Enago (www.enago. jp) and Textcheck (www. textcheck.com) for the English language review. The authors would like to thank the editor of this paper, Leo Oey, and two anonymous reviewers for their suggestions, which helped to improve the manuscript.

Open Access This article is distributed under the terms of the Creative Commons Attribution License which permits any use, distribution, and reproduction in any medium, provided the original author(s) and the source are credited.

\section{Appendixes}

Appendix A. 40- to 80-day fluctuation

We briefly describe the distribution of the 40- to 80-day fluctuations. Panels a and b of Fig. 21 show a composite 


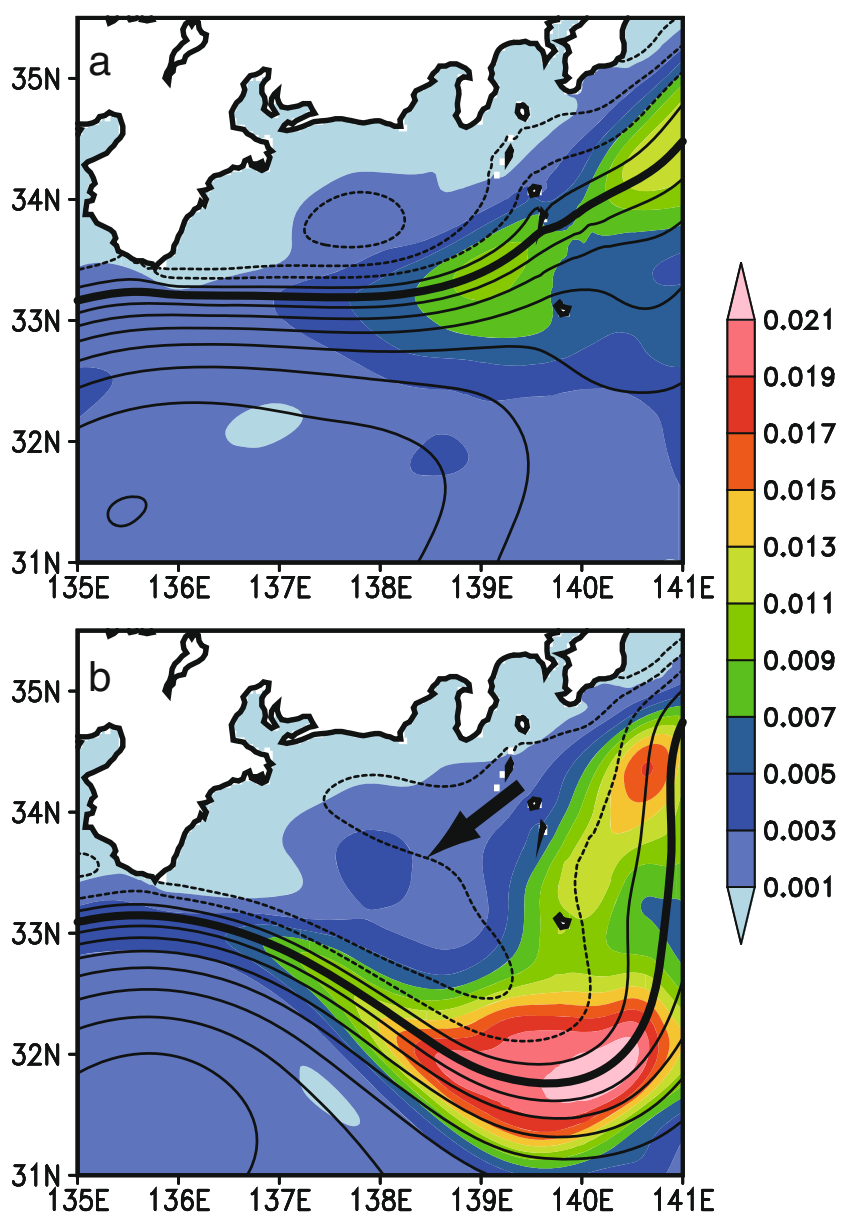

Fig. 21 Same as Fig. 7 except for the 40 - to 80-day period band

map of the 40- to 80-day fluctuations during NP and OP, respectively. In contrast to the 8- to 36-day fluctuations in Fig. 7, the peak variance of the 40- to 80-day fluctuations during OP (Fig. 21b) is higher than that during NP (Fig. 21a). The higher variance around the Izu Ridge during OP than NP is consistent with the observations of Kasai et al. (1993) and Takahashi et al. (2011).

Also in the Enshu-nada Sea (around $33.5^{\circ} \mathrm{N}, 138^{\circ} \mathrm{E}$ ), the variance of the 40 - to 80 -day fluctuations during OP is higher than that during NP. This is consistent with the past observation by Kasai et al. (1993), in that the westward intrusion of Kuroshio water into the Enshunada Sea often occurred with a 50-day period caused by the S-shaped meander of the Kuroshio path near the Izu Ridge. A vestige of the S-shaped meander can be seen in the time-averaged SSH during the OP in Fig. 21b (pointed at by the black arrow).

\section{Appendix B. Kuroshio path coordinate system}

In some of the analyses in this paper, a Kuroshio path coordinate system was used. This is because averages of variances and signals could become diffused in the fixed geophysical

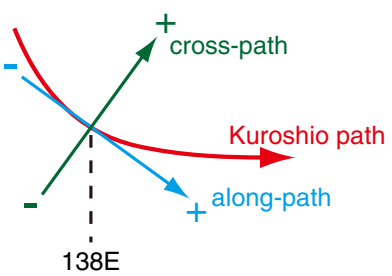

Fig. 22 Schematic diagram of the Kuroshio path coordinate system at $138^{\circ} \mathrm{E}$

coordinate system (Halkin and Rossby 1985; Howe et al. 2009) as the latitude and direction of the Kuroshio change with time. An example of the Kuroshio path coordinate system at $138^{\circ} \mathrm{E}$ is schematically shown in Fig. 22 . The Kuroshio path coordinate at $138^{\circ} \mathrm{E}$ means an origin is defined on the Kuroshio path at $138^{\circ} \mathrm{E}$. The along-path axis is oriented to the downstream tangential direction of the curve of the Kuroshio path. The cross-path axis is perpendicular to the along-path axis, and its direction is positive to the left of the along-path axis. In this paper, "inshore" and "offshore" directions are used interchangeably to mean "positive" and "negative" in the cross-pass direction, respectively. The latitude of the origin varies with time as the Kuroshio path moves. Although we could define the stream coordinate using the velocity direction like Halkin and Rossby (1985) and Howe et al. (2009), we used the curve of the Kuroshio path defined by the SSH isoline of $0.1 \mathrm{~m}$ for consistency with the other parts of this paper. The directions of the along-path and the maximum velocity at the surface agree well. Therefore, the velocity maximum at the surface in the Kuroshio path coordinate is around the origin (zero on the cross-path axis; Fig. 14e, f and Fig. $17 \mathrm{a}, \mathrm{c}$.$) . Because we are interested in the response of the$ short-term fluctuations to the low-frequency change of the background flow, we used the 90-day low-pass-filtered SSH rather than the instantaneous one. A similar method to investigate the variability along a slowly varying path was used by Tracey et al. (2012) in a study of the frontal waves in the Kuroshio Extension.

\section{References}

Awaji T, Akitomo K, Imasato N (1991) Numerical study of shelf water motion driven by the Kuroshio: Barotropic Model. J Phys Oceanogr 21(1):11-27. doi:10.1175/1520-0485(1991)021<0011:nsoswm $>2$. $0 . \operatorname{co} ; 2$

Feng M, Mitsudera H, Yoshikawa Y (2000) Structure and variability of the Kuroshio Current in Tokara Strait. J Phys Oceanogr 30(9):2257-2276. doi:10.1175/1520-0485(2000) $030<2257$ :savotk $>2.0 . \operatorname{co} ; 2$

Guo X, Hukuda H, Miyazawa Y, Yamagata T (2003) A triply nested ocean model for simulating the Kuroshio - roles of horizontal resolution on JEBAR. J Phys Oceanogr 33(1):146-169. doi:10.1175/ 1520-0485(2003)033<0146:atnomf>2.0.co;2 
Halkin D, Rossby T (1985) The structure and transport of the Gulf Stream at $73^{\circ} \mathrm{W}$. J Phys Oceanogr 15:1439-1452. doi:10.1175/15200485(1985)015<1439:tsatot $>2.0$.co;2

Hinata H, Yanagi T, Satoh C (2008) Sea level response to wind field fluctuation around the tip of the Izu Peninsula. J Oceanogr 64(4): 605-620. doi:10.1007/s10872-008-0051-z

Howe PJ, Donohue KA, Watts DR (2009) Stream-coordinate structure and variability of the Kuroshio extension. Deep-Sea Res I 56:10931116. doi:10.1016/j.dsr.2009.03.007

Itoh S, Sugimoto T (2008) Current variability of the Kuroshio near the separation point from the western boundary. J Geophys Res 113(C11):C11020-C11020. doi:10.1029/2007jc004682

James C, Wimbush M, Ichikawa H (1999) Kuroshio meanders in the East China Sea. J Phys Oceanogr 29(2):259-272. doi:10.1175/15200485(1999)029<0259:kmitec >2.0.co;2

Kalnay E, Kanamitsu M, Kistler R, Collins W, Deaven D, Gandin L, Iredell M, Saha S, White G, Woollen J, Zhu Y, Chelliah M, Ebisuzaki W, Higgins W, Janowiak J, Mo KC, Ropelewski C, Wang J, Leetmaa A, Reynolds R, Jenne R, Joseph D (1996) The NCEP/NCAR 40-year reanalysis project. Bull Am Meteorol Soc 77(3):437-471. doi:10.1175/1520-0477(1996) 077<0437:TNYRP $>2.0 . \mathrm{CO} ; 2$

Kasai A, Kimura S, Sugimoto T (1993) Warm water intrusion from the Kuroshio into the coastal areas south of Japan. J Oceanogr 49(6): 607-624. doi:10.1007/BF02276747

Kasai A, Kimura S, Nakata H, Okazaki Y (2002) Entrainment of coastal water into a frontal eddy of the Kuroshio and its biological significance. J Mar Syst 37(1-3):185-198. doi:10.1016/S0924-7963(02) 00201-4

Kawabe M (1985) Sea level variations at the Izu Islands and typical stable paths of the Kuroshio. J Oceanogr 41(5):307-326. doi:10.1007/ bf02109238

Kawabe M (1987) Spectral properties of sea level and time scales of Kuroshio path variations. J Oceanogr Soc Japan 43(2):111-123. doi: $10.1007 / \mathrm{bf02} 111887$

Kawabe M (1990) A steady model of typical non-large-meander paths of the Kuroshio Current. J Oceanogr Soc Japan 46(2):55-67. doi:10. $1007 / \mathrm{bf0} 2124815$

Kimura S, Sugimoto T (1987) Short period fluctuations in oceanographic and fishing conditions in the coastal area of Kumano-nada Sea. Nippon Suisan Gakkaishi 53(4):585-593, http://agriknowledge. affrc.go.jp/RN/2010350534.pdf

Kimura S, Sugimoto T (1993) Short-period fluctuations in meander of the Kuroshio path off Cape Shiono-misaki. J Geophys Res 98(C2): 2407-2418. doi:10.1029/92JC02582

Kimura S, Sugimoto T (2000) Two processes by which short-period fluctuations in the meander of the Kuroshio affect its countercurrent. Deep-Sea Res I 47(4):745-754. doi:10.1016/s0967-0637(99)00067-9

Kimura S, Choo HS, Sugimoto T (1994) Characteristics of the eddy caused by Izu-Oshima Island and the Kuroshio branch current in Sagami Bay, Japan. J Oceanogr 50(4):373-389. doi:10.1007/ BF02234961

Kimura S, Kasai A, Nakata H, Sugimoto T, Simpson JH, Cheok JVS (1997) Biological productivity of meso-scale eddies caused by frontal disturbances in the Kuroshio. ICES J Mar Sci 54(2):179192. doi:10.1006/jmsc. 1996.0209

Lee TN, Atkinson LP (1983) Low-frequency current and temperature variability from Gulf Stream frontal eddies and atmospheric forcing along the southeast U.S. outer continental shelf. J Geophys Res 88(C8):4541-4541. doi:10.1029/JC088iC08p04541

Maeda A, Yamashiro T, Sakurai M (1993) Fluctuation in volume transport distribution accompanied by the Kuroshio front migration in the Tokara Strait. J Oceanogr 49(2):231-245. doi:10.1007/bf02237290

Mitsudera H, Taguchi B, Waseda T, Yoshikawa Y (2006) Blocking of the Kuroshio large meander by baroclinic interaction with the Izu Ridge. J Phys Oceanogr 36(11):2042-2059. doi:10.1175/JPO2945.1
Miyama T, Miyazawa Y (2013) Structure and dynamics of the sudden acceleration of Kuroshio off Cape Shionomisaki. Ocean Dyn 63(23):265-281. doi:10.1007/s10236-013-0591-7

Miyazawa Y, Guo X, Yamagata T (2004) Roles of mesoscale eddies in the Kuroshio paths. J Phys Oceanogr 34(10):2203-2222. doi:10.1175/ 1520-0485(2004)034<2203:romeit>2.0.co;2

Miyazawa Y, Kagimoto T, Guo X, Sakuma H (2008) The Kuroshio large meander formation in 2004 analyzed by an eddy-resolving ocean forecast system. J Geophys Res 113(C10):C10015-C10015. doi:10. 1029/2007jc004226

Miyazawa Y, Zhang R, Guo X, Tamura H, Ambe D, Lee J-S, Okuno A, Yoshinari H, Setou T, Komatsu K (2009) Water mass variability in the western North Pacific detected in a 15-year eddy resolving ocean reanalysis. J Oceanogr 65(6):737-756. doi:10.1007/s10872-0090063-3

Oey L-Y (1988) A model of Gulf Stream frontal instabilities, meanders and eddies along the continental slope. J Phys Oceanogr 18(2):211229. doi:10.1175/1520-0485(1988)018<0211:amogsf $>2.0 . c 0 ; 2$

Oey L-Y, Chen P (1992) A nested-grid ocean model: with application to the simulation of meanders and eddies in the Norwegian Coastal Current. J Geophys Res 97(C12):20063-20086. doi:10.1029/ 92jc01991

Okazaki Y, Nakata H, Kimura S, Kasai A (2003) Offshore entrainment of anchovy larvae and its implication for their survival in a frontal region of the Kuroshio. Mar Ecol Prog Ser 248:237-244. doi:10. 3354/meps248237

Pedlosky J (1987) Geophysical fluid dynamics, 2nd edn. Springer, New York

Pratt LJ, Whitehead JA (2007) Rotating hydraulics: nonlinear topographic effects in the ocean and atmosphere. Springer, New York

Qiu B, Chen S (2005) Variability of the Kuroshio extension jet, recirculation gyre, and mesoscale eddies on decadal time scales. J Phys Oceanogr 35(11):2090-2103. doi:10.1175/jpo2807.1

Qiu B, Toda T, Imasato N (1990) On Kuroshio front fluctuations in the East China Sea using satellite and in situ observational data. J Geophys Res 95(C10):18191-18191. doi:10.1029/JC095iC10p18191

Ramp SR, Barrick DE, Ito T, Cook MS (2008) Variability of the Kuroshio Current south of Sagami Bay as observed using long-range coastal HF radars. J Geophys Res 113(C6):C06024-C06024. doi:10.1029/ 2007jc004132

Saito K, Ishida J-i, Aranami K, Hara T, Segawa T, Narita M, Honda Y (2007) Nonhydrostatic atmospheric models and operational development at JMA. J Meteorol Soc Jpn 85B:271-304. doi:10.2151/ jmsj.85B.271

Savidge DK (2004) Gulf stream meander propagation past Cape Hatteras. J Phys Oceanogr 34(9):2073-2085. doi:10.1175/1520-0485(2004) $034<2073$ :gsmppc $>2.0 . c 0 ; 2$

Sugimoto S, Hanawa K (2011) Relationship between the path of the Kuroshio in the south of Japan and the path of the Kuroshio Extension in the east. J Oceanogr 68(1):219-225. doi:10.1007/ s10872-011-0089-1

Sugimoto T, Kimura S, Miyaji K (1988) Meander of the Kuroshio front and current variability in the East China Sea. J Oceanogr Soc Japan 44(3):125-135. doi:10.1007/bf02302619

Taft AB (1978) Structure of the Kuroshio south of Japan. J Mar Res 16: $77-117$

Taira K, Teramoto T (1981) Velocity fluctuations of the Kuroshio near the Izu Ridge and their relationship to current path. Deep-Sea Res A 28(10):1187-1197. doi:10.1016/0198-0149(81)90055-8

Takahashi D, Morimoto A, Nakamura T, Hosaka T, Mino Y, Saino T (2011) Flow variability with periods of 50-70 days in Sagami Bay, Japan during the offshore non-large-meander path of the Kuroshio (in Japanese with English abstract and legends). Oceanogr Jpn 20(3, 4):59-83

Takahashi D, Morimoto A, Nakamura T, Hosaka T, Mino Y, Dang VH, Saino T (2012) Short-term flow and water temperature fluctuations 
in Sagami Bay, Japan, associated with variations of the Kuroshio during the non-large-meander path. Prog Oceanogr 105:47-60. doi: 10.1016/j.pocean.2012.04.012

Torrence C, Compo GP (1998) A practical guide to wavelet analysis. Bull Am Meteorol Soc 79(1):61-78. doi:10.1175/1520-0477(1998) 079<0061:apgtwa $>2.0 . c 0 ; 2$

Tracey KL, Watts DR (1986) On Gulf Stream meander characteristics near Cape Hatteras. J Geophys Res 91(C6):7587-7587. doi:10. 1029/JC091iC06p07587
Tracey KL, Watts DR, Donohue KA, Ichikawa H (2012) Propagation of Kuroshio extension meanders between $143^{\circ}$ and $149^{\circ}$ E. J Phys Oceanogr 42:581-601. doi:10.1175/jpo-d-11-0138.1

Waseda T, Mitsudera H (2002) Chaotic advection of the shallow Kuroshio coastal waters. J Oceanogr 58(5):627-638. doi:10.1023/ a: 1022882004769

Wells NC, Ivchenko VO, Best SE (2000) Instabilities in the Agulhas Retroflection Current system: a comparative model study. J Geophys Res 105(C2):3233-3241. doi:10.1029/1999jc900283 